This document is the accepted manuscript version of the following article:

Gimmi, T., \& Churakov, S. V. (2019). Water retention and diffusion in unsaturated clays: connecting atomistic and pore scale simulations. Applied Clay Science, 175, 169-183. https://doi.org/10.1016/ j.clay.2019.03.035

This manuscript version is made available under the CC-BY-NC-ND 4.0 1icense http://creativecommons.org/ 1icenses/by-nc-nd/4.0/

\title{
Water retention and diffusion in unsaturated clays: Connecting atomistic and pore scale simulations
}

\author{
Thomas Gimmi ${ }^{\mathrm{a}, \mathrm{b}, *}$, Sergey V. Churakov ${ }^{\mathrm{a}, \mathrm{b}}$ \\ ${ }^{a}$ Institute of Geological Sciences, University of Bern, CH-3012 Bern, Switzerland \\ ${ }^{b}$ Laboratory for Waste Management, Nuclear Energy and Safety, Paul Scherrer Institut, CH-5132 \\ Villigen, Switzerland
}

\begin{abstract}
Molecular diffusion is the dominant solute transport process in clays and claystones that are considered as sealing materials in the deep geological disposal of radioactive waste. These materials are typically water saturated, but during construction and later, at elevated temperatures or when gas may be produced, unsaturated conditions prevail. Investigating the clay's water retention properties as well as solute transport under unsaturated conditions is therefore mandatory. Here, functional dependencies of these properties were derived from atomistic and pore-scale simulations. In the absence of tomographic maps that resolve all pores in clays, model clay structure maps with different pore size distributions were generated using a previously developed algorithm. Upscaled water retention functions and upscaled diffusion coefficients of unsaturated samples were derived from these maps based on the shifted Young-Laplace equation that considers film adsorption and capillary condensation. Pore-scale parameters (diffusion coefficients, water film thickness) used for the upscaling were taken from molecular dynamics (MD) simulations, thus connecting MD and pore-scale simulations. We focused on effects of the pore size distribution and of the adsorbed water film on upscaled parameters. Samplescale diffusion coefficients were clearly reduced in unsaturated samples compared to the saturated state, with less reduction when including adsorbed water films. The reduction was stronger in samples with a narrow size distribution of the interparticle pores as compared to those with a wide distribution (but equal mean size). The results follow the trends of the experimental data, even though the scale of the simulations is still clearly smaller than that of typical experiments.
\end{abstract}

Keywords: claystone, water retention, diffusion, unsaturated, pore-scale modelling, upscaling

\footnotetext{
* Corresponding author

Email addresses: thomas.gimmi@geo.unibe.ch, thomas.gimmi@psi.ch (Thomas Gimmi), sergey.churakov@psi.ch (Sergey V. Churakov)
} 


\section{Introduction}

\section{1.1. Molecular diffusion in clays}

Molecular diffusion is typically the dominant mechanism for solute transport in low

4 permeability argillaceous rocks and in dense clays. Advective flow of water is absent or 5 negligible under natural hydraulic conditions (e.g., Patriarche et al., 2004; Gimmi et al.,

- 2007; Bensenouci et al., 2014). This is one of the reasons why claystones such as Opalinus

7 Clay, Callovo-Oxfordian clay or Boom Clay are considered as suitable host rocks for deep

8 geological disposal of radioactive waste. Similarly, clays with large smectite contents such

- as bentonite are foreseen as backfill in engineered barriers at disposal sites (e.g., Kaufhold

10 \& Dohrmann, 2016), and bentonite clay liners are used to cap surface landfills.

11 The performance of the clay barriers depends largely on their diffusion characteristics.

12 Accordingly, many studies focus on measuring the diffusion parameters of clays. Most of

13 the available data originate from tracer experiments in the laboratory (e.g., Kozaki et al.,

14 1999; Cormenzana et al., 2003; Cave et al., 2009; Glaus et al., 2010; Wittebroodt et al.,

15 2012; Joseph et al., 2013; Loomer et al., 2013; Xiang et al., 2013; Kulenkampff et al.,

16 2016; Lippmann-Pipke et al., 2017). These experiments provide valuable information for

17 the given tracer and the tested material at the scale of a single sample, but they are

18 time consuming. Furthermore, extrapolation of the data to larger scales, to a different

19 material or to a different tracer is not straightforward. In order to build up confidence

2o for long-term predictions of the performance of barriers, a thorough understanding of the

21 basic molecular mechanisms and of the interplay between - possibly evolving - struc-

22 tural and chemical properties of the clays and the diffusion of solutes has to be proven

23 The experimental studies need thus to be backed up with complementary, process-based numerical simulations.

\subsection{Approaches to upscale transport}

Following the idea of a "virtual rock laboratory", transport coefficients of a porous material at relevant scales $(\mathrm{cm}, \mathrm{m})$ may be calculated based on knowledge of microscopic features, notably pore-scale features such as the architecture or structure of the pore space (e.g., Tidwell \& Wilson, 2002; Cave et al., 2009; Gouze \& Luquot, 2011; Robinet et al., 2012; Andrä et al., 2013). Extending this idea further down to smaller scales, it is desirable to consider the molecular properties of the pore water, of the solutes, and of the solid interfaces as well when simulating sample-scale transport. Such upscaling over many orders of magnitude has not yet been accomplished in a self-consistent manner. However, there have been various successful attempts to upscale transport properties of clay materials over two or three characteristic scales, as outlined in the following.

Detailed information on local mobility of ions in different pores of clays can in principle be obtained by atomistic simulations. These simulations are particularly useful for understanding the ion transport in narrow pores close to the charged surface of clay particles. There, the behavior of ions is modulated by the structuring of the molecular solvent and the atomic scale roughness of the mineral surface. Due to the limited computational resources, such simulations are restricted to small pores up to few nanometers wide. Rotenberg et al. (2007b,a) used molecular dynamics (MD) simulations to obtain information about the mobility of ions in a diffuse double layer and to calculate the effective ionic potential across the interlayer pore of a clay particle. Pore-scale transport of ions was then modelled with a stochastic diffusion-reaction scheme considering 
46 retention of ions in the diffuse double layer. Large-scale parameters such as the sorption ${ }_{47}$ partitioning coefficient $\left(K_{d}\right)$, which represents the distribution of ions between the two 48 states 'sorbed' and 'in solution', as well as the exchange rates between these two states were then estimated from a solution of the mesoscopic continuum equations.

Transfer of the molecular simulation results to the laboratory scale needs an explicit 51 consideration of mineral grains and porosity distribution (Churakov \& Gimmi, 2011). In 52 the latter work, MD simulations were connected to pore-scale simulations in a two-step 53 approach. Local diffusion coefficients for specific pore environments, such as the edge region of montmorillonite particles and interlayer pores between basic clay layers, were obtained from MD simulations. They served then as input parameters in random walk

s6 pore-scale simulations, leading to diffusion coefficients at the sample scale. The latter 57 may alternatively be obtained by a homogenization approach (e.g., Tyagi et al., 2013), or

58 by a continuous-time Markovian particle-tracking scheme as presented in Cadini \& Zio

59 (2013). Experimentally observed features, such as anisotropy of diffusion or differences

Starting from pore-scale equations, Pivonka et al. (2009), Mohajeri et al. (2010), or Scheiner et al. (2013) used a homogenization approach to account for the ion distribution in diffuse double layers next to the charged surface of clay minerals. Mohajeri et al. (2010) showed that the diffusive ion flux in a channel with complex geometry can be described by a macroscopic diffusion equation using a generalized effective diffusion coefficient

${ }_{67}$ and an effective concentration in the pore space. The latter was obtained from the

${ }_{68}$ Poisson-Nernst-Planck equation, the former accounts for the geometric tortuosity and the deviation of the effective concentration from the actual averaged concentration.

Also starting from the pore scale, Obliger et al. (2013) extended a conventional lattice Boltzmann (LB) simulation scheme to account for transport of charged ions in an electrostatic potential exerted by a pore surface. The developed LB approach solves the Navier-Stokes equation coupled to the Poisson-Nernst-Planck equation. It was used to evaluate the validity range of the linearized Poisson-Boltzmann equation and to obtain coupling parameters between permeability and electrochemical transport parameters as function of surface charge and ion concentration. To mimic the transport in natural porous media at a sample scale, the pore space was modeled as a collection of spherical pores distributed on a rectangular mesh an interconnected by cylindrical channels. The size of spherical pores was varied to account for total porosity, whereas the channel width mainly determined the permeability. Such a simplistic representation of porous media allows for very fast evaluation of ion transport as a function of salt concentration and pressure gradient since the transport properties of interconnecting channels can be calculated in advance.

All pore-scale simulations rely on an explicit description of the pore network, i.e., of the arrangement of solids and pores on a grid (Churakov et al., 2014). Such pore maps are ideally derived directly from tomographic measurements. However, as clays and claystones have very narrow pores down to the nanometer range, direct visualization of the pore network of these materials is currently not yet possible. Instead, one has to rely on idealized or simulated model pore structure maps for the time being. Maps that satisfy known statistics of particle shapes, particle sizes, particle orientations and pore sizes were simulated for instance with kinetic Monte-Carlo or a lattice Boltzmann grain growth algorithms (Tyagi et al., 2013; Cartalade et al., 2016), and then used to 
93 predict transport coefficients. A particle deposition code was developed by Ferrage et al.

94 (2015) to mimic the sedimentation process of mono and poly-dispersed non-deformable,

95 disk-shaped clay particles. This algorithm led to model maps with characteristics (e.g., particle orientation distribution, pore size distribution) in good agreement with experimental data for vermiculite. Alternatively, pore network models were constructed from experimentally accessible characteristics of a claystone with pores down to the nanometer range in order to simulate diffusion of neutral or charged tracers (Jivkov \& Xiong, 2014; Xiong et al., 2016; Xiong \& Jivkov, 2018).

\subsection{Influence of partial saturation}

Approaches to upscale transport have so far focused on water saturated clays. Under natural conditions, potential clay host rocks as well as active clay liners or clay backfills are generally water saturated. During the construction of an underground repository, however, the contact with the unsaturated atmosphere leads to a partial desaturation of the rocks (e.g., Gimmi et al., 1997; Armand et al., 2016). Also, the bentonite backfill will be emplaced in a dry state, which may lead to a partial desaturation of the surrounding rock (e.g., Gens et al., 2002; Dessirier et al., 2016). A water-saturated state of the host rock and backfill materials will be achieved again some time after closure of the repository. Nevertheless, at the earlier stages, or later, when considerable amounts of gas are produced during certain phases, for instance through corrosion processes, unsaturated conditions may prevail.

The saturation state of the host rock and of the clayey backfill strongly affects thermal, hydraulic, mechanical, and transport properties (e.g., Revil, 2017) and generally the evolution of geochemical reactions in the barrier system. The water retention curve, also denoted as water characteristic function, is a central property. It gives the dependency between water content and applied suction. Water retention curves of Opalinus Clay were presented and discussed by Marschall et al. (2005), who conceptually characterized transport of gases in shales. Wan et al. (2013) and Ferrari et al. (2014) reported water retention curves for Callovo-Oxfordian samples and Opalinus Clay, respectively, considering also volume changes of the sample. Volume reductions were minor during desaturation from the initial state, but some swelling was observed when decreasing the suction compared to the initial state.

Jougnot et al. (2010) derived experimentally various hydraulic and transport parameters of Callovo-Oxfordien samples under partially saturated conditions, including the hydraulic conductivity, the specific storage, the streaming potential coupling coefficient, and the electrical conductivity. For instance, the relative hydraulic conductivity and the specific storage coefficient decreased strongly with decreasing saturation of the samples.

Savoye et al. $(2010,2012,2014,2017)$ investigated diffusion of a water tracer and of anions and cations through partially saturated samples of Callovo-Oxfordian claystone as well as through compacted clays with variable clay content. All diffusion coefficients $D_{e}$ were clearly reduced in partly saturated samples compared to fully saturated ones. The observed reduction in $D_{e}$ was larger for cations and anions as compared to water tracers, with factors up to 7 for water tracers and up to 60 for anions upon a reduction of the water saturation from 1 to 0.8 in the claystone. A new technique to estimate iodide diffusion coefficients in unsaturated claystones based on X-ray radiography was recently developed by Nunn et al. (2018). A reduction of $D_{e}$ values by about $20 \%$ for an average desaturation of 4 to 6-7\% of samples from a Canadian shale was reported. Desaturation 
was not homogeneous in these experiments, with lower desaturation in the center of the samples.

The effect of water saturation on the local diffusion coefficients of cations and water in a thin water film at the surface of montmorillonite was studied at the atomistic scale by MD simulations (Churakov, 2013). The predicted diffusivity of outer- and inner-sphere $\mathrm{Na}$ and Cs complexes, respectively, was hardly reduced compared to a fully saturated pore, as long as the montmorillonite surfaces were covered by at least two water layers. Averaged diffusivity of water was even increased in thin water films as compared to saturated conditions. These simulation results therefore suggest that the strong reduction of diffusion observed in unsaturated samples at the centimeter scale is probably mostly related to changes in the connectivity of the water-filled pore network.

\subsection{Capillary and film water retention}

At the continuum scale, desaturation of a sample is described by the water retention function. It gives the equilibrium relation between the water potential and the water saturation of the sample. The water potential can be connected to effective pore sizes through the capillary law. Capillary forces occur where water, air, and solid phases are in contact. In coarse-grained unsaturated porous materials, the water potential is mainly determined by capillary forces, and thus it suffices to consider these forces to model the water retention. In fine-grained wettable porous media such as clays, however, additional adsorptive forces that hold water in thin surface films have to be taken into account as well (e.g., Evans et al., 1986; Tuller et al., 1999). This phenomenon is well known and forms the basis for liquid and gas adsorption measurements (e.g., Gregg \& Sing, 1982). It is, for instance, explicitly taken into account when interpreting adsorption isotherms of a liquid on a porous sample in terms of the BJH algorithm to obtain pore size distributions (Barret et al., 1951). The thickness of liquid films depends on surface properties and varies as a function of the equilibrium water (or liquid) potential. Various empirical and theoretical relations exist that describe this dependency for different flat surfaces. For instance, data on the number of molecular liquid layers as a function of the liquid potential were derived from nitrogen isotherms by Pierce (1953), so-called $t$-curves for water adsorption were given by Hagymassy et al. (1969), or theoretical expressions based on van der Waals interactions were presented by Iwamatsu \& Horii (1996).

\subsection{Outline and aims of present work}

In this manuscript, water retention in clays was simulated taking into account surface water adsorption and capillary forces. Partially saturated model samples of clays are then used to upscale molecular diffusion coefficients as a function of water saturation. The procedure includes the following steps. (1) The thickness of a water film as a function of the water potential and the diffusion coefficient of water in adsorbed thin films was derived from Grand Canonical Monte Carlo (GCMC) and MD simulations (Churakov, 2013). (2) Two-dimensional structure maps representing clay samples with desired statistical properties were generated with a kinetic Monte Carlo grain growth algorithm described in Tyagi et al. (2013). (3) The maps were partially drained, based on the characteristics of the water films and the capillary law, to derive upscaled water retention functions . (4) Sample-scale diffusion coefficients for partially saturated samples were obtained applying random walk simulations. In this study $2 \mathrm{D}$ samples were 
considered only, but the approach can be extended to 3D. The main focus was on the role of interparticle pore size distribution and the effects of surface water films on the sample-scale diffusion coefficients under partially saturated conditions.

\section{Methods}

\subsection{Generation of clay structure maps}

A set of clay structure maps with heterogeneus pore and particle size distributions was generated according to the procedure given in Tyagi et al. (2013). Rectangular meshes of $16^{\prime} 000$ by $16^{\prime} 000$ pixels $\left(2.56 \cdot 10^{8}\right.$ pixels) representing a clay domain of 2000 by $2000 \mathrm{~nm}^{2}$ were created. This size is large enough to provide representative sampling statistics for a wide pore size distribution and ensures at the same time a fine spatial resolution (pixel size of $0.125 \mathrm{~nm}$ ).

In order to mimic elongated packages of single clay layers (stacks or aggregates of stacks) embedded in other material, as typically encountered in claystones (Keller et al., 2013; Houben et al., 2014; Hemes et al., 2015), the kinetic Monte Carlo (kMC) grain growth algorithm of Tyagi et al. (2013) was launched with two different particle populations. One population, representing clay particles, consisted initially of non-overlapping elliptic grains covering about $38 \%$ of the total sample area, with a mean elongation of $125 \mathrm{~nm}$, an average aspect ratio of 15 , and a uniform orientation distribution in the interval $\left(-22.5^{\circ},+22.5^{\circ}\right)$. The other population consisted initially of all other pixels. To each grain (ellipse or single pixel), an integer state ("spin") from the interval $[1,1000]$ was attributed. The total energy of the system is defined through a generalized Ising model with arbitrary spin number. The kMC grain growth algorithm then reduces an energy functional related to the interface area between different grains, and thus reduces the total interfacial area and increases the average size of grains (Tyagi et al., 2013). The algorithm was stopped when the mean area of non-elliptic grains reached $1 / 5$ of that of the elliptic grains, in order to mimic a clay with some larger smectite particles embedded in a matrix of smaller particles. The shape of the elliptic particles was modified in the growing process: they finally had a mean aspect ratio of $\sim 4$ and a mean elongation of $110 \mathrm{~nm}$ (Table 1).

Next, interlayer pores with an orientation along the longest axis of a particle, a width of $0.5 \mathrm{~nm}$, and a spacing of $1 \mathrm{~nm}$ between two interlayers were assigned to the originally elliptic clay particles. This configuration, denoted as "claystone", corresponds to a material with different particle types, including a large fraction of smectite particles with interlayer pores that accommodate two water layers. Alternatively, interlayers were assigned to all particles, leading to a material with only smectite particles ("smectite" configuration).

Finally, interparticle pores were created at boundaries of particles, with pore widths $w$ randomly drawn from a gamma distribution $\Gamma(k, \vartheta)$ with a specified mean size $E[w]=k \vartheta$ of $3 \mathrm{~nm}$ (similar as found for Opalinus Clay; Gimmi, 2003) and coefficients of variation $C V=k^{0.5}$ of $1.5,2,3,4,6,8$, and $10 . k[-]$ and $\vartheta[\mathrm{nm}]$ are the shape and scale parameter of the gamma distribution, respectively. The same mean size was used in the gamma (number) distributions, but the volume based mean pore size will slightly increase with $C V$, resulting from the larger volume fraction of a large pore compared to a small pore. Maps with widely varying pore size distributions were generated in this way. A small 
part of six of the seven structure maps is illustrated in Figure 1. The average properties of pore maps used in the simulations are summarized in Table 1.

\subsection{Water film thickness on clay surfaces and local film diffusion coefficients}

The thickness $t(r h)$ of the surface water film as a function of the relative humidity was derived from GCMC simulations reported in Churakov (2013). The average number of molecular water layers was calculated as the mass of water on an external montmorillonite surface divided by half of the mass of water in a saturated interlayer pore of $0.6 \mathrm{~nm}$ width. The latter represents two water layers, assuming $0.3 \mathrm{~nm}$ for the thickness of a single layer. For comparison, the statistical number of water layers in the interlayer pore was calculated as well from water densities at various relative humidities, with the surfaces being kept at a constant separation distance of $0.6 \mathrm{~nm}$ (i.e., no collapse was allowed).

The diffusion coefficients in films depend in general on film thickness and salt concentrations. Self-diffusion coefficients of water and cations in films on $\mathrm{Na}$ and $\mathrm{Cs}$ montmorillonite surfaces were obtained from MD simulations (Churakov, 2013). The simulations suggest that the average water diffusion in the film first increases during desaturation down to $r h \sim 0.3$ and then clearly decreases at drier conditions. The increase of the water mobility at initial stages of desaturation is related to higher mobility of loosely bound water molecules at the vapour-liquid phase boundary. At low water potential, the number of adsorbed water molecules is not sufficient to form a continuous water film. Instead, all water molecules form a first hydration shell of the ions and the effective mobility of water drops strongly. For the sake of simplicity, the dependence of water mobility on thickness of the adsorbed film was neglected and only two limiting cases were considered in the upscaling simulations: a water film having the same diffusion coefficient as the bulk of a pore, or no water film at all (equivalent to zero diffusion in the water film).

\subsection{Sample-scale water retention function}

The liquid-vapour interface in a single pore is considered as a surface of constant chemical potential or constant water potential. The water potential $\psi$ can be related to the relative humidity $r h$ of the vapour phase (which is equal to the water activity $a_{w}$ ) according to

$$
\psi=\frac{R T}{V_{w}} \ln (r h),
$$

with $V_{w}$ the molar volume of water, $R=8.314 \mathrm{~J} \mathrm{~mol}^{-1} \mathrm{~K}^{-1}$ the universal gas constant, and $T$ the temperature. The Young-Laplace equation (or capillary law) describes the relation between the radius $r_{K}$ of a capillary and the water potential, at which capillary condensation occurs, i.e., at which the capillary will switch from drained (which means dry in this context) to saturated or vice versa,

$$
\psi=-\frac{2 \sigma_{w} \cos \alpha}{r_{K}}
$$

with $\sigma_{w}$ the surface tension of water and $\alpha$ the wetting angle. Combining the two equations leads to the Kelvin equation that relates relative humidity $r h$ to the capillary (or Kelvin) radius $r_{K}$. The factor 2 should be dropped when slit-type pores are addressed explicitly (e.g., Evans \& Marini Bettolo Marconi, 1985; Gimmi, 2003). 
In addition to capillary forces, adsorptive forces also affect the pore water and lead to a liquid water film on a hydrophilic surface. The water potential can be represented as the sum of two components (assuming no other contributions), the adsorptive component $\psi_{a}$ and the capillary component $\psi_{c}$,

$$
\psi=\psi_{a}(t)+\psi_{c}\left(r_{K}\right) .
$$

This equation is known as unitary approach or augmented Young-Laplace (AYL) equation (Philip, 1977). The capillary component is related to the Kelvin radius $r_{K}$ according to the Young-Laplace equation. The adsorptive component is related to the thickness $t$ of the adsorbed water film as given by various empirical or theoretical expressions. For a flat surface, the FHH (Frenkel-Halsey-Hill) formalism is generally suited (e.g., Adamson \& Gast, 1997),

$$
\psi_{a}=-\frac{a}{V_{w}}\left(\frac{t}{t_{m}}\right)^{-b},
$$

where $t_{m}$ is the thickness of a monomolecular layer, $t / t_{m}=n$ the number of layers, and $a\left[\mathrm{~J} \mathrm{~mol}^{-1}\right]$ and $b[-]$ are parameters. For a thin flat film $(t \leq 20 \mathrm{~nm}), \psi_{a}$ can also be related to a Hamaker constant $A_{s l v}$ that describes the van der Waals interaction between a solid and a vapour phase across a liquid phase (Iwamatsu \& Horii, 1996; Israelachvili, 1991; Tokunaga, 2011; Leão \& Tuller, 2014),

$$
\psi_{a}=\frac{A_{s l v}}{6 \pi t^{3}} .
$$

Many other equations with similar functional dependencies between $\psi_{a}$ and $t$ exist. Eq. (3) allows then calculating the detailed configuration of the air-water interface in a single pore of complex geometry (Philip, 1977; Sweeney et al., 1993; Tuller et al., 1999), with water films being thinned or thickened at edges and corners, respectively. The solution of Eq. (3) is, however, too complex for a general use.

A much simpler approach is to consider capillary and adsorptive components independently to estimate the film thickness $t$ and the Kelvin radius $r_{K}$ at a given water potential, and to assume that the critical pore radius equals the sum of $t$ and $r_{K}$ (e.g., Barrett et al., 1951). As shown by Tuller et al. (1999), the detailed geometrical effects are of minor importance with respect to saturation of a pore, and the water configuration can be approximated by this so-called shifted Young-Laplace (SYL) equation. A pore of radius $r$ is completely saturated at a given water potential, when

$$
r \leq t(\psi)+r_{K}(\psi) \text {. }
$$

Otherwise, the central part of the pore with radius $r_{k}$ is drained but the pore surfaces are covered by a water film of thickness $t$.

This rule for drainage of pores at the pore scale was applied to the saturated clay structure maps to derive the sample-scale water retention function, i.e., the relation $S_{w}(r h)$, where $S_{w}=\theta / \theta_{s}$ is the water saturation, $\theta$ the water content, and $\theta_{s}$ the water content at saturation. For that purpose, first the distance transform (DT) of a structure map was derived using the image analysis software IDL ${ }^{\mathrm{TM}}$. The DT gives for every pore pixel in a map the minimum distance to a solid pixel, or, equivalently, the maximum circle that can be fully inscribed within the pore space at this location. Next, the equivalent 
pore size (PS) map was derived from the DT. The PS map gives for every pore pixel the maximum pore size to which this pixel can belong. Figure A.1 in the Appendix presents examples of a small part of a structure map and the corresponding DT and PS maps. Finally, the drainage pattern of a clay structure map was derived based on the PS map by a step-wise reduction of the water potential. Air was allowed to enter the pore network at each step, starting from the east and west, the north and south, or the front and distal boundary of the clay structure map, if condition (6) was no longer fulfilled ("air entry value") and continuity of the imbibing air phase to the boundary or another air-filled pore was given. For 2D maps, a drainage from the front and distal boundaries may lead to seemingly internal appearance of air, as illustrated in Figure 2.

The sample-scale water retention functions were calculated for all clay structure maps applying drainage from the frontal/distal sides, in order to compensate for the possibly underestimated pore connectivity in 2D maps. In this case, drying and wetting paths are identical, i.e., no hysteresis occurs. Water retention functions were obtained either considering or ignoring water films, with the thickness of the water film taken from the GCMC simulations. The water retention function is identical with a water desorption (or adsorption) isotherm. It can be interpreted as pore size distribution (PSD) that includes pore connectivities. This PSD deviates from the above mentioned PS map that ignores connectivity, if desaturation is only allowed from east/west or north/south sides, or if surface water films are included in the water retention model but not in the evaluation of the pore sizes. For real samples, the derivation of pore size distributions is often done without consideration of water films, but specific evaluation procedures such as the BJH algorithm correct for film contributions.

\subsection{Upscaled (sample-scale) diffusion coefficients}

The diffusion simulations at different saturation states were performed by a random walk algorithm, as described in Churakov \& Gimmi (2011) for saturated samples. Samples with an equilibrium water distribution at $r h=1.0,0.92,0.85$ and 0.43 were used, corresponding to water potentials of $0 \mathrm{MPa},-11.5 \mathrm{MPa},-22.4 \mathrm{MPa}$, and $-116 \mathrm{MPa}$ at $25^{\circ} \mathrm{C}$, respectively. Simulations for liquid water tracers and for dissolved anions were run for all structure maps at saturation and for a subset of the different $C V$ maps at lower $r h$, either including or excluding the surface water films.

Solid and air phases were considered as inaccessible. For a water tracer, identical diffusion coefficients $D_{0}$ of $2.3 \cdot 10^{-9} \mathrm{~m}^{2} \mathrm{~s}^{-1}$ were assigned to the central part of interparticle pores, to adsorbed water films, and to interlayer pores. Anion diffusion was investigated for the "claystone" maps only. As an approximation, anions were assumed to be completely excluded from interlayers (with two water layers) and from a fringe of $0.125 \mathrm{~nm}$ around smectite particles. The latter value may depend on the composition of the pore solution. A $D_{0}$ of $2.3 \cdot 10^{-9} \mathrm{~m}^{2} \mathrm{~s}^{-1}$ was used for the anions as well.

Sample-scale diffusion coefficients were calculated from the asymptotic slope of the mean square displacement of the walker particles against time. The slope was evaluated for $t>20 \mu \mathrm{s}$ (in two cases $t>40 \mu \mathrm{s}$ or $60 \mu \mathrm{s}$ ) to exclude the initially faster local diffusion. Upscaled diffusion coefficients are linearly related to the used local diffusion coefficient, as long as the same value is applied to all accessible regions, as is done here.

The upscaled diffusion coefficients represent pore diffusion coefficients $D_{p}$, which can be related to $D_{0}$ (the diffusion coefficient in bulk water, equal to the local diffusion 
coefficient used here) and the effective diffusion coefficient $D_{e}$ for instance as follows (e.g., Boving \& Grathwohl, 2001; Flury \& Gimmi, 2002):

$$
D_{e}=\theta_{a} D_{p}=\theta_{a} \frac{D_{0}}{\tau},
$$

where $\tau$ is the tortuosity or geometry factor including all geometrical effects on samplescale diffusion and $\theta_{a}$ is the accessible porosity or water content (or, more generally, a capacity term that may also be influenced by surface interactions).

\subsection{Important model assumption}

There is an important aspect of desaturation that needs to be mentioned here. Surface forces in clays or partly also in claystones can lead to shrinking or swelling of a sample. The loss or gain of water may be balanced by a change of the sample volume. The sample could then stay nearly saturated while changing its water content or void ratio (volume of voids per solid volume). In the model considered in this study such volume changes during desaturation are not allowed. The pore network and solid matrix remains rigid during the desaturation process.

For (over)consolidated claystones with low smectite contents, shrinkage may in fact be small and this simplification may be justified. Smectites exhibit more pronounced volume changes and also some internal reorganisation of structural parameters, depending on the interlayer cations (e.g., Bérend et al., 1995; Cases et al., 1997; Ferrage et al., 2005; Salles et al., 2008). Whereas for bivalent cations two-water layer hydrates dominate in the interlayer over a very broad range of water activities, the average interlayer hydration state for Na smectites changes as a function of $r h$, with interstratification of different hydration states occurring in both cases. Assuming a rigid structure may thus be less appropriate for Na smectites, and especially for water uptake at $r h \rightarrow 1$ under unconfined conditions.

Here we focus on aqueous diffusion in consolidated samples with comparably high density (Table1). Aqueous diffusion depends on the tortuosity and connectivity of the water phase and is strongly reduced when pores are drained or surface films are thinned, similarly as if drained pores reduced their size during shrinkage. Therefore, neglecting volume changes (within reasonable bounds) has only a limited effect on the diffusion of solutes. The situation may be different for gas transport, which depends on the network of gas-filled pore compartments and where neglecting volume changes (such as the collapse of a drained, gas-filled pore) may not always be justified.

\section{Results and Discussion}

\subsection{Water film thickness from MD simulations}

The numbers $n$ of average water layers on external surfaces of $\mathrm{Na}$ montmorillonite and of Cs montmorillonite (Churakov, 2013) at $r h<0.8$ were nearly identical (Figure 3, Table A.1 in the Appendix), even though hydration enthalpies of $\mathrm{Na}\left(-409 \mathrm{~kJ} \mathrm{~mol}^{-1}\right.$, Smith, 1977) and Cs $\left(-264 \mathrm{~kJ} \mathrm{~mol}^{-1}\right)$ vary considerably. Apparently, the film thickness at $r h<0.8$ depends mainly on the surface properties. It thus seems justified to use a thickness function independent of the charge compensating cation. The function increases in a sigmoidal way. At $r h$ values in the range where capillary condensation was expected 
to start in the modelled pore according to the Kelvin equation $(r h>0.85-0.9)$, the maximum number of 10 molecular water layers on each side of the $6 \mathrm{~nm}$ wide pore was indeed achieved. Liquid bridges or instabilities of the water films may already occur when the film thickness is about one third of the pore radius (Iwamatsu \& Horii, 1996; Tuller et al., 1999).

The number of water layers within the interlayer pore with a fixed width of $0.6 \mathrm{~nm}$ (Figure 3) decreased only marginally with $r h$, except for the lowest value, meaning that the water density in the interlayer of fixed width remained about constant. On the external surface, values of one water layer occur at $r h \approx 0.4$. Accordingly, the interlayer, being kept in a state of one layer on each side, is expected to have a tendency to shrink at $r h<0.4$, or to swell at $r h>0.4$, but such mechanical changes were not allowed in the present simulations.

For comparison, relations reported in the literature are also shown. The function derived from nitrogen adsorption data (Pierce, 1953), probably affected by some capillary condensation at $r h>0.8$, tends to overestimate the GCMC results at low $r h$. Relation (5) with a Hamaker constant $A_{s l v}$ of $6 \cdot 10^{-20} \mathrm{~J}$ as recommended for clays by Tuller \& Or (2005), Tokunaga (2011), or Leão \& Tuller (2014) exhibits a comparatively flat shape and thus tends to underestimate the simulated data at high $r h$ and to overestimate them at low $r h$. The average $t$-curve derived by Hagymassy et al. (1969) for water in samples with a BET energetic constant $C$ of 5.2 matches the simulated results quite well for $r h<0.8$. Figure 3 includes furthermore FHH curves (Eq. 4) fitted to the GCMC data for $r h<0.875$ (and extrapolated up to $r h=0.92$ for the external layer). A good match was obtained with the parameters given in Table A.1. These parameters and $t_{m}=0.3 \mathrm{~nm}$ were then used to simulate upscaled water retention functions.

\subsection{Upscaled water retention functions}

The shape of the water retention functions for the large "claystone" maps with heterogeneous particles (Figure 4) depends on the $C V$ of the gamma distribution used in the generating algorithm. For a large $C V$, desaturation occurs already at relatively high $r h$ or a relatively high water potential of about $-5 \mathrm{MPa}$ (air entry value), whereas for small $C V$ a more gradual desaturation with decreasing $r h$ is observed, and a lower air entry value down to about $-30 \mathrm{MPa}$. Air entry values in this order were reported, for instance, for Callovo Oxfordian claystone (Wan et al., 2013) or Opalinus Clay and a "Brown Dogger" sample (Marschall et al., 2005; Ferrari et al., 2014). A large $C V$ leads to a rather heterogeneous distribution of interparticle pores, with a few very large ones (Figure 1). The largest pores make up for a large fraction of the porosity, and accordingly the water saturation drops considerably as soon as these pores are drained at comparatively high $r h$.

Water saturation $S_{w}$ remained $>\sim 0.65$ in all cases for the "claystone" maps even at $r h<0.1$. This limit is given by their large fraction of interlayer pores with two water ayers, which would drain only at very low $r h$. The maps with only smectite particles have of course an even larger fraction of interlayer pore water. Consequently, the derived pore size distributions (PSDs, Figure 5) are dominated in all cases by the very small interlayer pores (large peak at $r \approx 0.3 \mathrm{~nm}$ ). Differences in the distributions occur only at larger pore sizes, with larger $C V$ s leading to a distribution skewed towards larger sizes.

The generated structure maps contain all a larger fraction of interlayer pores compared to natural claystones. Ignoring these interlayer pores, the PSD of the low to intermediate 
439 $C V$ maps in the mesopore range (1 nm $<r<25 \mathrm{~nm}$ ) have some similarity with that 440 of Opalinus Clay as derived from $\mathrm{Hg}$ injection (Figure 5). When comparing the curves, 441 one has to keep in mind, though, that the required drying as well as the high pressure 442 applied in $\mathrm{Hg}$ porosimetry may lead to a compaction of a clay sample. Accordingly, the 443 PSD derived from $\mathrm{Hg}$ injection may be shifted to smaller sizes compared to the original 444 pore sizes.

445 3.3. Upscaled unsaturated diffusion coefficients

446 3.3.1. General trends

${ }_{447}$ Overall, the simulated effective diffusion coefficients $D_{e}$ (Figure 6, Tables A.2-A.7)

448 follow roughly Archie's relation (1942) for saturated media,

$$
D_{e} / D_{0}=\theta_{a}^{m},
$$

450 with $\theta_{a}$ the accessible water content (equal to $\theta$ for water tracers) and $m$ the so-called 451 cementation factor. Coefficients parallel to bedding (i.e., along the mean orientation of 452 the originally elliptic grains) are larger by a factor of $\sim 2$ (anion, with $\theta_{a}<0.1$ here) to $453 \sim 4$ (water tracer, with $\theta_{a}>0.1$ ) than those perpendicular to bedding. This is consistent ${ }_{454}$ with experimental data from laboratory and field experiments (e.g., Gimmi et al., 2014).

$455 \quad$ Van Loon \& Mibus (2015) estimated $m$ for diffusion of HTO, iodide and chloride in 456 sedimentary rocks (perpendicular to bedding for anisotropic media) to be $\sim 2.4$, with a 457 range of about $2-3$. Our simulated data for "claystone" maps fall about in this range 458 (dashed lines in the figure). Simulated $D_{e} / D_{0}$ at lower accessible water contents tend 459 to deviate from a curve with constant $m$ towards larger values, similarly as observed for 460 experimental data by Van Loon \& Mibus (2015). These authors introduced an additional 461 term to Eq. (8) to account for this effect.

462 The values for the "smectite" maps $\left(\theta_{a}>0.3\right.$ here) tend to be low compared to a 463 curve with constant $m$. This is consistent with observations (e.g., Glaus et al., 2010)

464 that smectites have higher water contents than claystones, but comparably low diffusion 465 coefficients. The experimental data for Na-montmorillonite of Glaus et al. (2010) are 466 even lower than our simulated values for the "smectite" maps, whereas their kaolinite 467 and Na-illite data are in the range of the simulations for the "claystone" maps.

Smaller diffusion coefficients were obtained for structure maps with larger $C V$ of the 469 underlying gamma distribution for the interparticle pore sizes (trend shown by red arrow 470 in the figure). A larger $C V$ leads to more heterogeneous pore networks and thus to larger 471 tortuosities $\tau$.

472 Finally, diffusion coefficients decreased with desaturation (blue arrow), but following 473 a different trend compared to the Archie type curves. In the following three subsections, 474 the results for diffusion in unsaturated samples are discussed more in detail. We focus 475 on data parallel to bedding, but the observations apply equally to values perpendicular 476 to bedding, because the anisotropy ratios remained nearly constant with desaturation.

477 3.3.2. Water diffusion in unsaturated samples

$478 \quad$ A pronounced drop of $D_{e} / D_{e, s a t}$ (Figure 7a,b; $D_{e, s a t}$ is $D_{e}$ at saturation $S_{w}=1$ )

479 already at small desaturations occurs for maps with the smallest $C V(1.5,2)$ of the interparticle pore size distribution. These maps are characterized by a comparatively narrow 

$517 \theta_{a}$

pore size distribution. When pores in this size range start to drain, the diffusion coefficient drops clearly. In contrast, maps with a large $C V$ (but same mean pore size) have a few clearly larger pores. Draining these few larger pores leads to a clear desaturation but affects $D_{e}$ only slightly. Diffusion of water is then still dominated by the connected, saturated network of smaller pores.

Surface water films increase simulated unsaturated $D_{e}$ in all cases (dashed lines in Figure $7 \mathrm{a}, \mathrm{b})$. The increase is more pronounced for the "claystone" samples than for the "smectite" samples. In the latter, diffusion is mainly controlled by the (saturated) interlayer pores anyway. The increase is also more pronounced for samples with low $C V$. This is related to their comparatively narrow pore size distribution. The effect of a concurrent desaturation of a large fraction of pores is moderated by the surface films: they increase the connectivity of the remaining saturated pores.

\subsubsection{Anion diffusion in unsaturated samples}

Qualitatively, diffusion of anions in "claystone" maps (Figure 7c) is affected by desaturation in the same way as that of water tracers, but the decrease of $D_{e} / D_{e, s a t}$ is more pronounced. Anions were excluded from all interlayer pores (and from a small fringe around the smectite particles). Accordingly, diffusion of anions depends directly on the connectivity of the interparticle pores. Draining some of these pores will have a more pronounced effect on diffusion of anions compared to water tracers.

Interestingly, consideration of surface water films has a similar effect as for water diffusion, except for the $C V 1.5$ map. There, the increase of $D_{e}$ by the films is much smaller than for water diffusion. For this map, a clear desaturation occurs only at the lowest relative humidity $r h=0.43$, but not at $r h=0.92$ and 0.85 (cf. Figure 4 ). The capillary radius $r_{k}$ at $r h=0.43$ equals $1.3 \mathrm{~nm}$, the film thickness $t 0.26 \mathrm{~nm}$. This very thin film (about the size of a water molecule), which is furthermore blocked for anions around smectite particles, can only weakly increase anion diffusion. The maps with larger $C V$ start to drain already at $r h=0.92$ and 0.85 . At these humidities, the film thickness equals $1.3 \mathrm{~nm}$ and $0.82 \mathrm{~nm}$, respectively (and the capillary radius $13.2 \mathrm{~nm}$ and $6.8 \mathrm{~nm}$, respectively). The surface water films at these $r h$ then significantly increase the connectivity for anion diffusion in these maps.

The simulated anion accessible pore water fraction $f_{a}=\theta_{a} / \theta$ decreases clearly with desaturation in all cases (Figure 8) from $\sim 0.4$ at $S_{w}=1$ to $\sim 0.1$ at a $S_{w}=0.7$, with only small absolute differences between the different $C V$ maps. Essentially no difference occurs between cases without and with film, in contrast to the observation for $D_{e}$. This demonstrates that the films affect $D_{e}$ of anions mainly by increasing the continuity of the liquid phase (decreasing $\tau$ ), but hardly by increasing the anion accessible porosity $\theta_{a}$.

A constant, small anion inaccessible fringe around the smectite particles was used in the simulations, independent of the saturation of the pore and the surface film thickness. This must be considered as a rough approximation for several reasons. On a molecular scale, anion accessibility is not a step function, and the (average) accesibility of water near a charged surface generally depends on the solution composition. Moreover, drainage of the core of a pore may - depending on the drainage process - alter the solution composition within the film and thus the accessibility of the film to anions. Both, the film and the exclusion model could be extended by linking it to the solution chemistry (Tokunaga, 2011). The present simulations with the small anion inaccessible fringe, 
546 or

or

without films and with films, can be considered as limiting cases valid for not too dilute solution concentrations.

\subsubsection{Comparison with experimental data and with empirical models for unsaturated samples}

The simulated $D_{e} / D_{e, s a t}$ of "claystone" maps with low $C V$, but not with high $C V$, capture approximately the trends of experimental data measured for unsaturated samples of Callovo Oxfordian claystone (Savoye et al., 2010) and of illite/sand mixtures (ratio 80/20 and 60/40; Savoye et al., 2014; Figure 7b and c). The simulated diffusion coefficients of anions decreased more prominently upon desaturation than those of HTO, consistent with the experimental observations. Also, as in the experiments, the simulated anion accessible pore fraction $f_{a}$ decreased upon desaturation (Figure 8), albeit less pronounced than in the Callovo Oxfordian claystone. One has to bear in mind that our "claystone" maps differ with respect to several parameters from the experimental samples (e.g., larger smectite content, larger porosity, probably smaller mean pore size). Thus, one should only compare trends, but not absolute values.

The stronger decrease of simulated $D_{e}$ during drainage (see 3.3.1) than predicted by Archie's relation for saturated samples with $m=2.5$ is in agreement with experiments. Archie (1942) presented also a relation for unsaturated samples that can be given as

$$
D_{e} / D_{0}=\theta_{s}^{m} S_{w}^{n}
$$

with $S_{w}$ the water saturation and $n$ a parameter $(\sim 2$ for his investigated unconsolidated and consolidated sands). From the simulation results, $n$ values between about 0.7 and 10 are obtained, with larger values (about consistent with the value of 9.3 for the CallovoOxfordian data) for lower $C V$ and without film diffusion. For anions, it could be more reasonable to use $S_{w a}=\theta_{a} / \theta_{a s}$, the anion accessible water saturation, instead of $S_{w}$ in Eq. 10. This would lead to lower $n$ values. The range of available saturations is not sufficient to rigorously test the validity of relation (10). It appears that a more complex form is required in general, possibly including a threshold saturation below which diffusion completely ceases. Savoye et al. (2014) applied such a modified form to obtain a better match with their data, but the necessary parameters could not be well constrained due to the limited number of data points available.

\section{Summary and Conclusions}

Following the idea of a 'virtual rock laboratory', an approach was presented to simulate water retention curves and diffusion coefficients of unsaturated clay samples. It includes (1) generation of clay structure maps with a previously published kinetic grain growth algorithm, (2) deriving required local parameters (here the thickness of surface water films in unsaturated pores) from molecular simulations, (3) applying a desaturation algorithm considering capillary condensation and film adsorption according to the SYL method, and finally (4) performing random walk simulations in fully and partially saturated clay structure maps. 
Overall, the set of all simulated diffusion coefficients broadly follows the empirical first Archie's relation with an exponent of $2-2.5$, similarly as found for measured data for clays. Desaturation reduced diffusion coefficients of each investigated subset (structure map, tracer) more strongly than predicted just by applying Archie's first relation, as was also found experimentally. To capture this behavior, Archie's second relation or an extended version thereof is required, possibly including a threshold water saturation.

The simulations could reproduce essential features observed in experiments with various clay materials. Similar air-entry values as reported for Opalinus Clay or Callovo Oxfordian claystone were derived from the upscaled water retention functions. The simulated reduction of diffusion upon desaturation was more pronounced for an anion tracer as compared to a water tracer, in agreement with experimental findings for HTO and iodide in various clay materials.

Both, the water retention function and the effect of pore drainage on diffusion depend on the heterogeneity and the topology of the considered pore network. Experimental water retention functions of Opalinus Clay and of Callovo Oxfordian claystone could approximately be reproduced with "claystone" maps having low to intermediate coefficients of variations of the interparticle pore size distributions $(C V \sim 2-4)$, if their content of smectite particles with interlayer pores was reduced. Experimental unsaturated diffusion data for Callovo Oxfordian claystone and illite/sand mixtures could also be best reproduced by simulations with "claystone" maps with $C V \sim 1.5-4$, that is, having a limited heterogeneity of interparticle pore sizes. Due to the still comparably small size of the maps, it was, however, not possible to test the effect of additional micrometer-sized pores on water retention and diffusion.

Surface films had an important effect on simulated diffusion coefficients in unsaturated samples. In order to judge their importance for experimentally derived data, more detailed clay structure maps are needed, because the upscaling results strongly depend on the pore size variability and the pore connectivity of the used structure maps. Ideally, tomographic representations of the pore space at different scales should be used for this purpose in the future. The proposed algorithms can then be directly applied to calculate upscaled parameter sets for various tracers under partially saturated conditions.

\section{Acknowledgement}

Partial financial support by Nagra, the Swiss Cooperative for the Disposal of Radioactive Waste, is gratefully acknowledged.

\section{Appendix}

The procedure to derive pore size distributions from clay structure maps through distance transform (DT) maps and pore size (PS) maps is illustrated in Figure A.1. The DT map gives for every pore pixel the minimum distance to a solid pixel, the PS map the maximum pore size to which this pixel can belong. The water retention curve was then obtained from the PS map while considering the connectivity of the pores. It thus represents a pore size distribution that includes connectivity effects.

Water retention curves ignoring or including thin surface water films were generated, the latter according to the shifted Young-Laplace (SYL) equation (Eq. 6). Including 
610 surface water films does affect water retention functions not only through the additional

611 amount of water in the films, but also through a shift of the drainage of pores to smaller

${ }_{612}$ relative humidities (or smaller water potentials). This is illustrated for a small part of a

613 pore map in Figure A.2.

${ }_{614}$ The average number of water layers $n$ on $\mathrm{Na}$ and $\mathrm{Cs}$ montorillonite surfaces derived

615 from MD simulations (Figure 3) and used in the determination of water retention curves

616 through the SYL equation are listed in Table A.1, together with the corresponding fit

617 parameters. All derived unsaturated diffusion coefficients in the different model clay

${ }_{618}$ structures and the corresponding (tracer accessible) water contents and anisotropy ratios

shown in Figures 7 and 8 are listed in Tables A.2 to A.7.

\section{References}

621 Adamson, A. W., \& Gast, A. P. (1997). Physical Chemistry of Surfaces, 6th ed.. Wiley.

622 Andrä, H., Combaret, N., Dvorkin, J., Glatt, E., Han, J., Kabel, M., Keehm, Y., Krzikalla, F., Lee, M., 623 Madonna, C., Marsh, M., Mukerji, T., Saenger, E. H., Sain, R., Saxena, N., Ricker, S., Wiegmann,

624 A., \& Zhan, X. (2013). Digital rock physics benchmarks-part ii: Computing effective properties. 625 Computers \& Geosciences, 50, 33-43. doi:10.1016/j.cageo.2012.09.008.

626 Archie, G. E. (1942). The electrical resistivity log as an aid in determining some reservoir characteristics. 627 Transactions of the American Institute of Mining and Metallurgical Engineers, 146, 54-61.

628 Armand, G., Djizanne, H., Zghondi, J., de La Vaissiere, R., Talandier, J., \& Conil, N. (2016).

629 Inputs from in situ experiments to the understanding of the unsaturated behaviour of callovo-

630 oxfordian claystone. 3rd European Conference on Unsaturated Soils - E-unsat 2016, 9, UNSP 03004 631 doi:10.1051/e3sconf/20160903004.

632 Barrett, E. P., Joyner, L. G., \& Halenda, P. P. (1951). The determination of pore volume and area 633 distributions in porous substances .1. computations from nitrogen isotherms. Journal of the American 634 Chemical Society, 73, 373-380. doi:10.1021/ja01145a126.

635 Bensenouci, F., Michelot, J. L., Matray, J. M., Savoye, S., Massault, M., \& Vinsot, A. (2014). Coupled study of water-stable isotopes and anions in porewater for characterizing aqueous transport through the Mesozoic sedimentary series in the eastern Paris Basin. Marine and Petroleum Geology, 53, 88-101. doi:10.1016/j.marpetgeo.2013.12.012.

9 Bérend, I., Cases, J. M., François, M., Uriot, J. P., Michot, L., Masion, A., \& Thomas, F. (1995). Mechanism of adsorption and desorption of water-vapor by homoionic montmorillonites. 2 . $\mathrm{The} \mathrm{Li}^{+}$, $\mathrm{Na}^{+}, \mathrm{K}^{+}, \mathrm{Rb}^{+}$and $\mathrm{Cs}^{+}$-exchanged forms. Clays and Clay Minerals, 43, 324-336.

42 Boving, T. B., \& Grathwohl, P. (2001). Tracer diffusion coefficients in sedimentary rocks: correlation between porosity and hydraulic conductivity. Journal of Contaminant Hydrogeology, 53(1), 85-100.

44 Cadini, F., \& Zio, E. (2013). Simulation of reactive diffusion in clays by a continuous-time markovian particle-tracking scheme. Journal of Physical Chemistry C, 117, 18510-18519. doi:10.1021/jp405520v

646 Cartalade, A., Younsi, A., \& Plapp, M. (2016). Lattice boltzmann simulations of 3d crystal growth:

647 Numerical schemes for a phase-field model with anti-trapping current. Computers 6 Mathematics with Applications, 71, 1784-1798. doi:10.1016/j.camwa.2016.02.029.

49 Cases, J. M., Bérend, I., François, M., Uriot, J. P., Michot, L. J., \& Thomas, F. (1997). Mechanism of

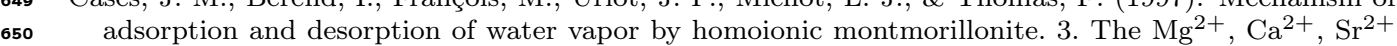
and $\mathrm{Ba}^{2+}$ exchanged forms. Clays and Clay Minerals, 45, 8-22.

52 Cave, L., Al, T., Xiang, Y., \& Vilks, P. (2009). A technique for estimating one-dimensional diffusion coefficients in low-permeability sedimentary rock using x-ray radiography: Comparison with through-diffusion measurements. Journal of Contaminant Hydrology, 103, 1-12. doi:10.1016/j.jconhyd.2008.08.001.

656 Churakov, S. V. (2013). Mobility of na and cs on montmorillonite surface under partially saturated conditions. Environmental Science \& Technology, 47, 9816-9823. doi:10.1021/es401530n.

658 Churakov, S. V., \& Gimmi, T. (2011). Up-scaling of molecular diffusion coefficients in clays: A two-step approach. Journal of Physical Chemistry C, 115, 6703-6714. doi:10.1021/jp112325n.

o Churakov, S. V., Gimmi, T., Unruh, T., Van Loon, L. R., \& Jurányi, F. (2014). Resolving diffusion in clay minerals at different time scales: Combination of experimental and modeling approaches. Applied Clay Science, 96, 36-44. doi:10.1016/j.clay.2014.04.030. 
Cormenzana, J. L., Garcia-Gutierrez, M., Missana, T., \& Junghanns, A. (2003). Simultaneous estimation of effective and apparent diffusion coefficients in compacted bentonite. Journal of Contaminant Hydrology, 61, 63-72.

Dessirier, B., Frampton, A., Fransson, A., \& Jarsjo, J. (2016). Modeling early in situ wetting of a compacted bentonite buffer installed in low permeable crystalline bedrock. Water Resources Research, 52, 6207-6221. doi:10.1002/2016WR018678.

Evans, R., \& Marini Bettolo Marconi, U. (1985). The role of wetting films in capillary condensation and rise - influence of long-range forces. Chemical Physics Letters, 114, 415-422. doi:10.1016/00092614(85)85111-3

Evans, R., Marini Bettolo Marconi, U., \& Tarazona, P. (1986). Fluids in narrow pores - adsorption, capillary condensation, and critical-points. Journal of Chemical Physics, 84, $2376-2399$. doi:10.1063/1.450352.

Ferrage, E., Hubert, F., Tertre, E., Delville, A., Michot, L. J., \& Levitz, P. (2015). Modeling the arrangement of particles in natural swelling-clay porous media using three-dimensional packing of elliptic disks. Physical Review E, 91, 062210. doi:10.1103/PhysRevE.91.062210.

Ferrage, E., Lanson, B., Sakharov, B. A., \& Drits, V. A. (2005). Investigation of smectite hydration properties by modeling experimental X-ray diffraction patterns: Part I. Montmorillonite hydration properties. American Mineralogist, 90, 1358-1374.

Ferrari, A., Favero, V., Marschall, P., \& Laloui, L. (2014). Experimental analysis of the water retention behaviour of shales. International Journal of Rock Mechanics and Mining Sciences, 72, 61-70. doi:10.1016/j.ijrmms.2014.08.011.

Flury, M., \& Gimmi, T. (2002). Solute Diffusion. In J. Dane, \& G. Topp (Eds.), Methods of Soil Analysis, Part 4-Physical Methods chapter 6.2. (pp. 1323-1351). Madison, Wisconsin, USA: Soil Science Society of America Inc.

Gens, A., Guimaraes, L. D., Garcia-Molina, A., \& Alonso, E. E. (2002). Factors controlling rock-clay buffer interaction in a radioactive waste repository. Engineering Geology, 64, 297-308.

Gimmi, T. (2003). Porosity, pore structure, and energy state of pore water of Opalinus Clay from Benken. Nagra Internal Report NIB 03-09 Nagra, Wettingen, Switzerland.

Gimmi, T., Leupin, O. X., Eikenberg, J., Glaus, M. A., Van Loon, L. R., Waber, H. N., Wersin, P., Wang, H. A. O., Grolimund, D., Borca, C. N., Dewonck, S., \& Wittebroodt, C. (2014). Anisotropic diffusion at the field scale in a 4-year multi-tracer diffusion and retention experiment - I: Insights from the experimental data. Geochimica et Cosmochimica Acta, 125, 373-393. URL: http://www.sciencedirect.com/science/article/pii/S001670371300570X. doi:dx.doi.org/10.1016/j.gca.2013.10.014.

Gimmi, T., Schneebeli, M., Flühler, H., Wydler, H., \& Baer, T. (1997). Field-scale water transport in unsaturated crystalline rock. Water Resources Research, 33, 589-598.

Gimmi, T., Waber, H. N., Gautschi, A., \& Rübel, A. (2007). Stable water isotopes in pore water of Jurassic argillaceous rocks as tracers for solute transport over large spatial and temporal scales. Water Resources Research, 43, W04410.

Glaus, M. A., Frick, S., Rosse, R., \& Van Loon, L. R. (2010). Comparative study of tracer diffusion of HTO, $(22) \mathrm{Na}(+)$ and $(36) \mathrm{Cl}(-)$ in compacted kaolinite, illite and montmorillonite. Geochimica et Cosmochimica Acta, 74, 1999-2010. doi:10.1016/j.gca.2010.01.010.

Gouze, P., \& Luquot, L. (2011). X-ray microtomography characterization of porosity, permeability and reactive surface changes during dissolution. Journal of Contaminant Hydrology, 120-21, 45-55. doi:10.1016/j.jconhyd.2010.07.004.

Gregg, S. J., \& Sing, K. (1982). Adsorption, surface area, and porosity. (2nd ed.). Academic Press Inc, London.

Hagymassy, J., Brunauer, S., \& Mikhail, R. S. (1969). Pore structure analysis by water vapor adsorption. I. T-curves for water vapor. Journal of Colloid and Interface Science, 29, 485-+. doi:10.1016/00219797(69)90132-5.

Hemes, S., Desbois, G., Urai, J. L., Schroppel, B., \& Schwarz, J. O. (2015). Multi-scale characterization of porosity in boom clay (hades-level, mol, belgium) using a combination of x-ray mu-ct, 2d bib-sem and fib-sem tomography. Microporous and Mesoporous Materials, 208, 1-20. doi:10.1016/j.micromeso.2015.01.022.

Houben, M. E., Desbois, G., \& Urai, J. L. (2014). A comparative study of representative 2d microstructures in shaly and sandy facies of opalinus clay (mont terri, switzerland) inferred form bib-sem and mip methods. Marine and Petroleum Geology, 49, 143-161. doi:10.1016/j.marpetgeo.2013.10.009.

Israelachvili, J. N. (1991). Intermolecular and Surfaces Forces, 2nd ed.. Academic Press, London, U.K. Iwamatsu, M., \& Horii, K. (1996). Capillary condensation and adhesion of two wetter surfaces. Journal 
722 of Colloid and Interface Science, 182, 400-406. doi:10.1006/jcis.1996.0480.

723 Jivkov, A. P., \& Xiong, Q. R. (2014). A network model for diffusion in media with partially resolvable pore space characteristics. Transport in Porous Media, 105, 83-104. doi:10.1007/s11242-014-0360-1.

Joseph, C., Van Loon, L. R., Jakob, A., Steudtner, R., Schmeide, K., Sachs, S., \& Bernhard, G. (2013). Diffusion of $\mathrm{u}(\mathrm{vi})$ in opalinus clay: Influence of temperature and humic acid. Geochimica et Cosmochimica Acta, 109, 74-89. doi:10.1016/j.gca.2013.01.027.

Jougnot, D., Revil, A., Lu, N., \& Wayllace, A. (2010). Transport properties of the callovooxfordian clay rock under partially saturated conditions. Water Resources Research, 46. doi:10.1029/2009WR008552.

Kaufhold, S., \& Dohrmann, R. (2016). Distinguishing between more and less suitable bentonites for storage of high-level radioactive waste. Clay Minerals, 51, 289-302. doi:10.1180/claymin.2016.051.2.14.

Keller, L. M., Holzer, L., Schuetz, P., \& Gasser, P. (2013). Pore space relevant for gas permeability in opalinus clay: Statistical analysis of homogeneity, percolation, and representative volume element. Journal of Geophysical Research-Solid Earth, 118, 2799-2812. doi:10.1002/jgrb.50228.

Kozaki, T., Sato, Y., Nakajima, M., Kato, H., Sato, S., \& Ohashi, H. (1999). Effect of particle size on the diffusion behavior of some radionuclides in compacted bentonite. Journal of Nuclear Materials, 270, 265-272

Kulenkampff, J., Zakhnini, A., Grundig, M., \& Lippmann-Pipke, J. (2016). Quantitative experimental monitoring of molecular diffusion in clay with positron emission tomography. Solid Earth, 7, 12071215. doi:10.5194/se-7-1207-2016.

Leão, T. P., \& Tuller, M. (2014). Relating soil specific surface area, water film thickness, and water vapor adsorption. Water Resources Research, 50, 7873-7885. doi:10.1002/2013WR014941.

Lippmann-Pipke, J., Gerasch, R., Schikora, J., \& Kulenkampff, J. (2017). Benchmarking pet for geoscientific applications: 3d quantitative diffusion coefficient determination in clay rock. Computers $\&$ Geosciences, 101, 21-27. doi:10.1016/j.cageo.2017.01.002.

Loomer, D. B., Scott, L., Al, T. A., Mayer, K. U., \& Bea, S. (2013). Diffusion-reaction studies in low permeability shale using X-ray radiography with cesium. Applied Geochemistry, 39, 49-58. doi:10.1016/j.apgeochem.2013.09.019.

Marschall, P., Horseman, S., \& Gimmi, T. (2005). Characterisation of gas transport properties of the Opalinus Clay, a potential host rock formation for radioactive waste disposal. Oil E Gas Science and Technology - Revue de l'Institut Français du Pétrole, 60, 121-139.

Mohajeri, A., Narsilio, G. A., Pivonka, P., \& Smith, D. W. (2010). Numerical estimation of effective diffusion coefficients for charged porous materials based on micro-scale analyses. Computers and Geotechnics, 37, 280-287. doi:10.1016/j.compgeo.2009.10.004.

Nunn, J. A., Xiang, Y., \& Al, T. A. (2018). Investigation of partial water saturation effects on diffusion in shale. Applied Geochemistry, 97, 93-101. doi:10.1016/j.apgeochem.2018.08.004.

Obliger, A., Duvail, M., Jardat, M., Coelho, D., Bekri, S., \& Rotenberg, B. (2013). Numerical homogenization of electrokinetic equations in porous media using lattice-boltzmann simulations. Physical Review E, 88, 013019. doi:10.1103/PhysRevE.88.013019.

Patriarche, D., Ledoux, E., Michelot, J. L., Simon-Coincon, R., \& Savoye, S. (2004). Diffusion as the main process for mass transport in very low water content argillites: 2 . Fluid flow and mass transport modeling. Water Resources Research, 40, W01517.

Philip, J. R. (1977). Unitary approach to capillary condensation and adsorption. Journal of Chemical Physics, 66, 5069-5075. doi:10.1063/1.433814.

Pierce, C. (1953). Computation of pore sizes from physical adsorption data. Journal of Physical Chemistry, 57, 149-152. doi:10.1021/j150503a005.

Pivonka, P., Narsilio, G. A., Li, R. N., Smith, D. W., \& Gardiner, B. (2009). Electrodiffusive transport in charged porous media: From the particle-level scale to the macroscopic scale using volume averaging. Journal of Porous Media, 12, 101-118. doi:10.1615/JPorMedia.v12.i2.10.

Revil, A. (2017). Transport of water and ions in partially water-saturated porous media. Part 1. Constitutive equations. Advances in Water Resources, 103, 119-138. doi:10.1016/j.advwatres.2016.02.006.

Robinet, J.-C., Sardini, P., Coelho, D., Parneix, J.-C., Pret, D., Sammartino, S., Boller, E., \& Altmann, S. (2012). Effects of mineral distribution at mesoscopic scale on solute diffusion in a clay-rich rock: Example of the callovo-oxfordian mudstone (bure, france). Water Resources Research, 48, W05554. doi:10.1029/2011WR011352.

Rotenberg, B., Marry, V., Dufreche, J.-F., Malikova, N., Giffaut, E., \& Turq, P. (2007a). Modelling water and ion diffusion in clays: A multiscale approach. Comptes Rendus Chimie, 10, 1108-1116. doi:10.1016/j.crci.2007.02.009.

Rotenberg, B., Marry, V., Vuilleumier, R., Malikova, N., Simon, C., \& Turq, P. (2007b). Water and 
ions in clays: Unraveling the interlayer/micropore exchange using molecular dynamics. Geochimica et Cosmochimica Acta, 71, 5089-5101. doi:10.1016/j.gca.2007.08.018.

Salles, F., Beurroies, I., Bildstein, O., Jullien, M., Raynal, J., Denoyel, R., \& Van Damme, H. (2008). A calorimetric study of mesoscopic swelling and hydration sequence in solid na-montmorillonite. Applied Clay Science, 39, 186-201. doi:10.1016/j.clay.2007.06.001.

Savoye, S., Beaucaire, C., Fayette, A., Herbette, M., \& Coelho, D. (2012). Mobility of cesium through the callovo-oxfordian claystones under partially saturated conditions. Environmental Science 89 Technology, 46, 2633-2641. doi:10.1021/es2037433.

Savoye, S., Imbert, C., Fayette, A., \& Coelho, D. (2014). Experimental study on diffusion of tritiated water and anions under variable water-saturation and clay mineral content: comparison with the callovo-oxfordian claystones. Clays In Natural and Engineered Barriers For Radioactive Waste Confinement. Geological Society, London, Special Publications, 400, 579-588. doi:10.1144/SP400.9.

Savoye, S., Lefevre, S., Fayette, A., \& Robinet, J.-C. (2017). Effect of water saturation on the diffusion/adsorption of $22 \mathrm{na}$ and cesium onto the callovo-oxfordian claystones. Geofluids, 2017, 17. URL: https://doi.org/10.1155/2017/1683979. doi:10.1155/2017/1683979.

Savoye, S., Page, J., Puente, C., Imbert, C., \& Coelho, D. (2010). New experimental approach for studying diffusion through an intact and unsaturated medium: A case study with callovo-oxfordian argillite. Environmental Science \& Technology, 44, 3698-3704. doi:10.1021/es903738t.

Scheiner, S., Pivonka, P., \& Smith, D. W. (2013). Electro-diffusive transport in macroscopic porous media: Estimation of effective transport properties using numerical upscaling. Computers and Geotechnics, 48, 283-292. doi:10.1016/j.compgeo.2012.08.002.

Smith, D. W. (1977). Ionic hydration enthalpies. Journal of Chemical Education, 54, 540-542. doi:10.1021/ed054p540.

Sweeney, J. B., Davis, T., Scriven, L. E., \& Zasadzinski, J. A. (1993). Equilibrium thin-films on rough surfaces .1. capillary and disjoining effects. Langmuir, 9, 1551-1555. doi:10.1021/la00030a021.

Tidwell, V. C., \& Wilson, J. L. (2002). Visual attributes of a rock and their relationship to permeability: A comparison of digital image and minipermeameter data. Water Resources Research, 38, 1261. doi:10.1029/2001WR000932.

Tokunaga, T. K. (2011). Physicochemical controls on adsorbed water film thickness in unsaturated geological media. Water Resources Research, 47, W08514. doi:10.1029/2011WR010676.

Tuller, M., \& Or, D. (2005). Water films and scaling of soil characteristic curves at low water contents. Water Resources Research, 41, W09403. doi:10.1029/2005WR004142.

Tuller, M., Or, D., \& Dudley, L. M. (1999). Adsorption and capillary condensation in porous media: Liquid retention and interfacial configurations in angular pores. Water Resources Research, 35, 19491964. doi:10.1029/1999WR900098.

Tyagi, M., Gimmi, T., \& Churakov, S. V. (2013). Multi-scale micro-structure generation strategy for up-scaling transport in clays. Advances in Water Resources, 59 , 181-195. URL: http://www.sciencedirect.com/science/article/pii/S0309170813001036. doi:10.1016/j.advwatres.2013.06.002.

Van Loon, L. R., \& Mibus, J. (2015). A modified version of archie's law to estimate effective diffusion coefficients of radionuclides in argillaceous rocks and its application in safety analysis studies. Applied Geochemistry, 59, 85-94. doi:10.1016/j.apgeochem.2015.04.002.

Wan, M., Delage, P., Tang, A. M., \& Talandier, J. (2013). Water retention properties of the callovooxfordian claystone. International Journal of Rock Mechanics and Mining Sciences, 64, 96-104. doi:10.1016/j.ijrmms.2013.08.020.

Wittebroodt, C., Savoye, S., Frasca, B., Gouze, P., \& Michelot, J. . L. (2012). Diffusion of HTO, Cl-36(-) and I-125(-) in Upper Toarcian argillite samples from Tournemire: Effects of initial iodide concentration and ionic strength. Applied Geochemistry, 27, 1432-1441. doi:10.1016/j.apgeochem.2011.12.017.

Xiang, Y., Al, T., Scott, L., \& Loomer, D. (2013). Diffusive anisotropy in low-permeability ordovician sedimentary rocks from the michigan basin in southwest ontario. Journal of Contaminant Hydrology, 155, 31-45. doi:10.1016/j.jconhyd.2013.09.002.

Xiong, Q., Jivkov, A. P., \& Ahmad, S. M. (2016). Modelling reactive diffusion in clays with two-phaseinformed pore networks. Applied Clay Science, 119, 222-228. doi:10.1016/j.clay.2015.10.013.

Xiong, Q. R., \& Jivkov, A. P. (2018). Anion diffusion in clay-rich sedimentary rocks - a pore network modelling. Applied Clay Science, 161, 374-384. doi:10.1016/j.clay.2018.05.010. 
Table 1: Parameters for generation of the clay structure maps and average geometrical properties of the final maps.

\begin{tabular}{|c|c|c|c|}
\hline $\begin{array}{l}\text { Domain properties } \\
\text { Domain size } \\
\text { Resolution }\end{array}$ & \multicolumn{3}{|c|}{$\begin{array}{l}16000 \times 16000 \times 1 \text { pix, } 2000 \times 2000 \times 0.125 \mathrm{~nm}^{3} \\
0.125 \mathrm{~nm} \mathrm{pix}^{-1}\end{array}$} \\
\hline $\begin{array}{l}\text { Initial configuration for grain grow } \\
\text { Major axis, nm } \\
\text { Minor axis, nm } \\
\text { Aspect ratio, - } \\
\text { Circularity, - } \\
\text { Area, nm }{ }^{2} \\
\text { Orientation, }{ }^{\circ} \\
\text { Area fraction, - } \\
\text { Interlayer width, nm } \\
\quad d \text {-value, } \mathrm{nm} \\
\text { Interparticle pores: } E[w]^{a}, \mathrm{~nm} \\
\qquad \mathrm{CV}^{b}\end{array}$ & $\begin{array}{c}h \text { and pore generat } \\
\text { Clay grains } \\
125 \\
8.33 \\
15 \\
0.162 \\
818 \\
U(-22.5,+22.5) \\
0.1\end{array}$ & $\begin{array}{c}\text { on algorithm } \\
\text { Other grains } \\
0.125 \\
0.125 \\
1 \\
1 \\
0.0123 \\
0.9\end{array}$ & $\begin{array}{c}\text { Pores } \\
\\
\\
\\
\\
0.5 \\
1.5 \\
3 \\
1.5,2,3,4,6,8,10\end{array}$ \\
\hline $\begin{array}{l}\text { Average properties of final structur } \\
\text { Major axis, nm } \\
\text { Minor axis, nm } \\
\text { Aspect ratio, - } \\
\text { Circularity, - } \\
\text { Area, nm² } \\
\text { Orientation, }{ }^{\circ} \\
\text { Area fraction, - } \\
\text { hereof interlayer porosity } \\
\text { Interparticle porosity, - } \\
\text { Total porosity, - } \\
\text { Bulk dry density }{ }^{e}, \mathrm{~g} \mathrm{~cm}^{3}\end{array}$ & $\begin{array}{l}\text { maps } \\
\text { Clay grains } \\
110 \\
29.4 \\
3.73 \\
0.326 \\
2572 \\
\sim U(-25,+25) \\
0.353 \\
0.118\end{array}$ & $\begin{array}{c}\text { Other grains } \\
26.2 \\
15.9 \\
1.65 \\
0.506 \\
454 \\
\\
0.564 \\
0^{c} / 0.188^{d}\end{array}$ & $\begin{array}{c}0.083 \\
0.200^{c} / 0.389^{d} \\
2.24^{c} / 1.71^{d}\end{array}$ \\
\hline
\end{tabular}


Table A.1: Average number of water layers $n$ on surfaces of $\mathrm{Na}$ and $\mathrm{Cs}$ montmorillonite obtained from MD simulations (Churakov 2013, incl. some additional values). The data for Na montmorillonite surfaces can be described by an FHH function with the given parameters (but note that this function is not the best choice for interlayers).

\begin{tabular}{cccc}
\hline$r h$ & Na-mnt, external & Na-mnt, internal & Cs-mnt, external \\
\hline 0.0155 & $0.347 \pm 0.038$ & $1.142 \pm 0.109$ & 0.3 \\
0.0820 & $0.456 \pm 0.059$ & $1.689 \pm 0.066$ & 0.4 \\
0.2230 & $0.656 \pm 0.130$ & $1.852 \pm 0.058$ & 0.7 \\
0.4344 & $0.992 \pm 0.147$ & $1.933 \pm 0.054$ & 1.0 \\
0.6064 & $1.567 \pm 0.262$ & $1.972 \pm 0.055$ & 1.4 \\
0.7164 & $2.275 \pm 0.364$ & $2.002 \pm 0.049$ & 2.2 \\
0.7787 & $3.047 \pm 1.220$ & $1.993 \pm 0.057$ & 3.3 \\
0.8464 & $3.551 \pm 0.577$ & $2.004 \pm 0.048$ & 6.0 \\
0.8751 & $4.093 \pm 0.845$ & $2.029 \pm 0.023$ & \\
0.9048 & $4.155 \pm 0.809$ & $2.043 \pm 0.006$ & \\
0.9355 & $9.833 \pm 0.109$ & $1.996 \pm 0.039$ & \\
\cline { 1 - 2 } Fitted parameters $^{a}$ for FHH function (Eq. 4$)$ & \\
\cline { 1 - 2 }$a$, J mol $^{-1}$ & $2486 \pm 248$ & $6.5 \cdot 10^{5} \pm 1.2 \cdot 10^{6}$ & \\
$b,-$ & $1.40 \pm 0.08$ & $10.0 \pm 3.0$ &
\end{tabular}

${ }^{a}$ Data at $r h<0.875$ used for fitting, but function extrapolated to $r h 0.92$ for diffusion simulations; see text 
Table A.2: Simulated water diffusion parameters for saturated and unsaturated "smectite" samples without surface water films ( $D_{e x}$ is parallel to bedding, $D_{e y}$ perpendicular to bedding).

\begin{tabular}{|c|c|c|c|c|c|c|c|c|}
\hline$C V$ & $r h$ & $\theta$ & $S_{w}$ & $D_{e x} / D_{0}$ & $D_{e y} / D_{0}$ & $D_{e x} / D_{e x, s a t}$ & $D_{e y} / D_{e y, s a t}$ & $D_{e x} / D_{e y}$ \\
\hline \multirow[t]{4}{*}{1.5} & 1 & 0.3839 & 1 & 0.1212 & 0.0303 & 1 & 1 & 3.99 \\
\hline & 0.9190 & 0.3839 & 1 & & & & & \\
\hline & 0.8445 & 0.3834 & 0.9988 & & & & & \\
\hline & 0.4295 & 0.3489 & 0.9089 & & & & & \\
\hline \multirow[t]{3}{*}{2} & 1 & 0.3858 & 1 & 0.1173 & 0.0292 & 1 & 1 & 4.02 \\
\hline & 0.8445 & 0.3810 & 0.9876 & 0.1137 & 0.0280 & 0.9692 & 0.9596 & 4.06 \\
\hline & 0.4295 & 0.3406 & 0.8829 & 0.0481 & 0.0114 & 0.4104 & 0.3891 & 4.24 \\
\hline \multirow[t]{4}{*}{3} & 1 & 0.3889 & 1 & 0.1122 & 0.0272 & 1 & 1 & 4.12 \\
\hline & 0.9190 & 0.3880 & 0.9977 & & & & & \\
\hline & 0.8445 & 0.3725 & 0.9578 & & & & & \\
\hline & 0.4295 & 0.3321 & 0.8538 & & & & & \\
\hline \multirow[t]{4}{*}{4} & 1 & 0.3927 & 1 & 0.1076 & 0.0264 & 1 & 1 & 4.07 \\
\hline & 0.9190 & 0.3831 & 0.9757 & 0.1013 & 0.0251 & 0.9415 & 0.9496 & 4.04 \\
\hline & 0.8445 & 0.3606 & 0.9183 & 0.0873 & 0.0215 & 0.8112 & 0.8137 & 4.06 \\
\hline & 0.4295 & 0.3269 & 0.8326 & 0.0485 & 0.0115 & 0.4505 & 0.4344 & 4.22 \\
\hline \multirow[t]{4}{*}{6} & 1 & 0.3932 & 1 & 0.1065 & 0.0256 & 1 & 1 & 4.16 \\
\hline & 0.9190 & 0.3734 & 0.9496 & 0.0952 & 0.0225 & 0.8942 & 0.8795 & 4.23 \\
\hline & 0.8445 & 0.3463 & 0.8806 & 0.0761 & 0.0183 & 0.7146 & 0.7136 & 4.16 \\
\hline & 0.4295 & 0.3243 & 0.8247 & 0.0528 & 0.0127 & 0.4954 & 0.4941 & 4.17 \\
\hline \multirow[t]{4}{*}{8} & 1 & 0.3905 & 1 & 0.1038 & 0.0255 & 1 & 1 & 4.07 \\
\hline & 0.9190 & 0.3667 & 0.9391 & & & & & \\
\hline & 0.8445 & 0.3412 & 0.8736 & & & & & \\
\hline & 0.4295 & 0.3249 & 0.8319 & & & & & \\
\hline \multirow[t]{4}{*}{10} & 1 & 0.3847 & 1 & 0.0995 & 0.0237 & 1 & 1 & 4.20 \\
\hline & 0.9190 & 0.3593 & 0.9340 & 0.0883 & 0.0206 & 0.8874 & 0.8697 & 4.29 \\
\hline & 0.8445 & 0.3382 & 0.8792 & 0.0761 & 0.0178 & 0.7650 & 0.7535 & 4.27 \\
\hline & 0.4295 & 0.3277 & 0.8520 & 0.0608 & 0.0144 & 0.6107 & 0.6080 & 4.22 \\
\hline
\end{tabular}


Table A.3: Simulated water diffusion parameters for saturated and unsaturated "claystone" samples without surface water films ( $D_{e x}$ is parallel to bedding, $D_{e y}$ perpendicular to bedding).

\begin{tabular}{|c|c|c|c|c|c|c|c|c|}
\hline$C V$ & $r h$ & $\theta$ & $S_{w}$ & $D_{e x} / D_{0}$ & $D_{e y} / D_{0}$ & $D_{e x} / D_{e x, s a t}$ & $D_{e y} / D_{e y, s a t}$ & $D_{e x} / D_{e y}$ \\
\hline \multirow[t]{4}{*}{1.5} & 1 & 0.1946 & 1 & 0.0395 & $9.67 \mathrm{e}-3$ & 1 & 1 & 4.08 \\
\hline & 0.9190 & 0.1946 & 1 & & & & & \\
\hline & 0.8445 & 0.1942 & 0.9981 & & & & & \\
\hline & 0.4295 & 0.1628 & 0.8366 & $8.00 \mathrm{e}-3$ & $1.84 \mathrm{e}-3$ & 0.2027 & 0.1899 & 4.36 \\
\hline \multirow[t]{4}{*}{2} & 1 & 0.1972 & 1 & 0.0359 & $8.54 \mathrm{e}-3$ & 1 & 1 & 4.20 \\
\hline & 0.9190 & 0.1971 & 0.9994 & & & & & \\
\hline & 0.8445 & 0.1927 & 0.9772 & & & & & \\
\hline & 0.4295 & 0.1546 & 0.7841 & & & & & \\
\hline \multirow[t]{4}{*}{3} & 1 & 0.2014 & 1 & 0.0316 & $7.35 \mathrm{e}-3$ & 1 & 1 & 4.30 \\
\hline & 0.9190 & 0.2006 & 0.9956 & & & & & \\
\hline & 0.8445 & 0.1856 & 0.9213 & & & & & \\
\hline & 0.4295 & 0.1466 & 0.7277 & & & & & \\
\hline \multirow[t]{4}{*}{4} & 1 & 0.2061 & 1 & 0.0288 & $7.07 \mathrm{e}-3$ & 1 & 1 & 4.07 \\
\hline & 0.9190 & 0.1968 & 0.9548 & 0.0265 & $6.50 \mathrm{e}-3$ & 0.9213 & 0.9185 & 4.08 \\
\hline & 0.8445 & 0.1746 & 0.8472 & 0.0216 & $5.19 \mathrm{e}-3$ & 0.7522 & 0.7342 & 4.17 \\
\hline & 0.4295 & 0.1420 & 0.6891 & $8.56 \mathrm{e}-3$ & $1.77 \mathrm{e}-3$ & 0.2975 & 0.2503 & 4.84 \\
\hline \multirow[t]{4}{*}{6} & 1 & 0.2074 & 1 & 0.0288 & $6.52 \mathrm{e}-3$ & 1 & 1 & 4.42 \\
\hline & 0.9190 & 0.1878 & 0.9053 & & & & & \\
\hline & 0.8445 & 0.1610 & 0.7763 & & & & & \\
\hline & 0.4295 & 0.1396 & 0.6731 & & & & & \\
\hline \multirow[t]{4}{*}{8} & 1 & 0.2020 & 1 & 0.0276 & $6.28 \mathrm{e}-3$ & 1 & 1 & 4.40 \\
\hline & 0.9190 & 0.1785 & 0.8838 & & & & & \\
\hline & 0.8445 & 0.1532 & 0.7583 & & & & & \\
\hline & 0.4295 & 0.1373 & 0.6796 & & & & & \\
\hline \multirow[t]{4}{*}{10} & 1 & 0.1940 & 1 & 0.0253 & $5.83 \mathrm{e}-3$ & 1 & 1 & 4.35 \\
\hline & 0.9190 & 0.1689 & 0.8707 & 0.0211 & $4.85 \mathrm{e}-3$ & 0.8308 & 0.8315 & 4.35 \\
\hline & 0.8445 & 0.1481 & 0.7634 & 0.0175 & $3.95 \mathrm{e}-3$ & 0.6893 & 0.6774 & 4.43 \\
\hline & 0.4295 & 0.1377 & 0.7100 & 0.0132 & $3.05 \mathrm{e}-3$ & 0.5197 & 0.5231 & 4.32 \\
\hline
\end{tabular}


Table A.4: Simulated anion diffusion parameters for saturated and unsaturated "claystone" samples without surface water films ( $D_{e x}$ is parallel to bedding, $D_{e y}$ perpendicular to bedding). For corresponding water contents and water saturations see Table A.3 with results for water tracers.

\begin{tabular}{|c|c|c|c|c|c|c|c|c|c|}
\hline$C V$ & $r h$ & $\theta_{a}$ & $f_{a}$ & $S_{w a}$ & $D_{e x} / D_{0}$ & $D_{e y} / D_{0}$ & $D_{e x} / D_{e x, s a t}$ & $D_{e y} / D_{e y, s a t}$ & $D_{e x} / D_{e y}$ \\
\hline \multirow[t]{4}{*}{1.5} & 1 & 0.0704 & 0.3616 & 1 & $9.50 \mathrm{e}-03$ & $4.05 \mathrm{e}-03$ & 1 & 1 & 2.34 \\
\hline & 0.9190 & 0.0704 & 0.3616 & 1 & & & & & \\
\hline & 0.8445 & 0.0698 & 0.3596 & 0.9926 & & & & & \\
\hline & 0.4295 & 0.0367 & 0.2252 & 0.5212 & $3.89 \mathrm{e}-04$ & $2.04 \mathrm{e}-04$ & 0.0409 & 0.0503 & 1.91 \\
\hline \multirow[t]{4}{*}{2} & 1 & 0.0732 & 0.3714 & 1 & $7.44 \mathrm{e}-03$ & $3.17 \mathrm{e}-03$ & 1 & 1 & 2.35 \\
\hline & 0.9190 & 0.0731 & 0.3710 & 0.9983 & & & & & \\
\hline & 0.8445 & 0.0686 & 0.3558 & 0.9362 & & & & & \\
\hline & 0.4295 & 0.0298 & 0.1926 & 0.4067 & & & & & \\
\hline \multirow[t]{4}{*}{3} & 1 & 0.0779 & 0.3869 & 1 & & & & & \\
\hline & 0.9190 & 0.0771 & 0.3842 & 0.9886 & & & & & \\
\hline & 0.8445 & 0.0616 & 0.3318 & 0.7900 & & & & & \\
\hline & 0.4295 & 0.0228 & 0.1558 & 0.2929 & & & & & \\
\hline \multirow[t]{4}{*}{4} & 1 & 0.0835 & 0.4053 & 1 & $5.09 \mathrm{e}-03$ & $2.13 \mathrm{e}-03$ & 1 & 1 & 2.38 \\
\hline & 0.9190 & 0.0739 & 0.3756 & 0.8849 & $4.65 \mathrm{e}-03$ & $1.99 \mathrm{e}-03$ & 0.9143 & 0.9299 & 2.34 \\
\hline & 0.8445 & 0.0514 & 0.2944 & 0.6154 & $3.18 \mathrm{e}-03$ & $1.47 \mathrm{e}-03$ & 0.6256 & 0.6901 & 2.16 \\
\hline & 0.4295 & 0.0194 & 0.1370 & 0.2328 & $5.09 \mathrm{e}-04$ & $2.41 \mathrm{e}-04$ & 0.1000 & 0.1129 & 2.11 \\
\hline \multirow[t]{4}{*}{6} & 1 & 0.0844 & 0.4070 & 1 & $4.32 \mathrm{e}-03$ & $1.96 \mathrm{e}-03$ & 1 & 1 & 2.21 \\
\hline & 0.9190 & 0.0645 & 0.3433 & 0.7636 & & & & & \\
\hline & 0.8445 & 0.0378 & 0.2348 & 0.4478 & & & & & \\
\hline & 0.4295 & 0.0169 & 0.1213 & 0.2006 & & & & & \\
\hline \multirow[t]{4}{*}{8} & 1 & 0.0804 & 0.3978 & 1 & $4.04 \mathrm{e}-03$ & $1.88 \mathrm{e}-03$ & 1 & 1 & 2.14 \\
\hline & 0.9190 & 0.0566 & 0.3168 & 0.7040 & & & & & \\
\hline & 0.8445 & 0.0314 & 0.2049 & 0.3906 & & & & & \\
\hline & 0.4295 & 0.0160 & 0.1168 & 0.1995 & & & & & \\
\hline \multirow[t]{4}{*}{10} & 1 & 0.0716 & 0.3692 & 1 & $3.72 \mathrm{e}-03$ & $1.66 \mathrm{e}-03$ & 1 & 1 & 2.25 \\
\hline & 0.9190 & 0.0462 & 0.2736 & 0.6453 & $3.03 e-03$ & $1.33 \mathrm{e}-03$ & 0.8146 & 0.8031 & 2.28 \\
\hline & 0.8445 & 0.0256 & 0.1725 & 0.3567 & $2.21 \mathrm{e}-03$ & $9.57 \mathrm{e}-04$ & 0.5935 & 0.5779 & 2.31 \\
\hline & 0.4295 & 0.0157 & 0.1142 & 0.2196 & $1.28 \mathrm{e}-03$ & $5.61 \mathrm{e}-04$ & 0.3433 & 0.3388 & 2.28 \\
\hline
\end{tabular}


Table A.5: Simulated water diffusion parameters for unsaturated "smectite" samples with surface water films ( $D_{e x}$ is parallel to bedding, $D_{e y}$ perpendicular to bedding).

\begin{tabular}{ccccccccc}
\hline$C V$ & $r h$ & $\theta$ & $S_{w}$ & $D_{e x} / D_{0}$ & $D_{e y} / D_{0}$ & $D_{e x} / D_{e x, s a t}$ & $D_{e y} / D_{e y, s a t}$ & $D_{e x} / D_{e y}$ \\
\hline 2 & 0.8445 & 0.3829 & 0.9924 & 0.1172 & 0.0290 & 0.9993 & 0.9912 & 4.05 \\
& 0.4295 & 0.3493 & 0.9054 & 0.0859 & 0.0203 & 0.7324 & 0.6962 & 4.22 \\
\multirow{2}{*}{4} & & & & & & & & \\
& 0.9190 & 0.3869 & 0.9852 & 0.1064 & 0.0260 & 0.9882 & 0.9845 & 4.09 \\
& 0.8445 & 0.3676 & 0.9362 & 0.0999 & 0.0244 & 0.9282 & 0.9231 & 4.09 \\
& 0.4295 & 0.3331 & 0.8483 & 0.0742 & 0.0180 & 0.6897 & 0.6799 & 4.13 \\
6 & 0.9190 & 0.3801 & 0.9665 & 0.1027 & 0.0246 & 0.9637 & 0.9597 & 4.18 \\
& 0.8445 & 0.3538 & 0.8998 & 0.0931 & 0.0222 & 0.8744 & 0.8676 & 4.19 \\
& 0.4295 & 0.3288 & 0.8361 & 0.0703 & 0.0167 & 0.6598 & 0.6522 & 4.21 \\
& & & & & & & & \\
& 0.9190 & 0.3675 & 0.9554 & 0.0956 & 0.0227 & 0.9608 & 0.9585 & 4.21 \\
& 0.8445 & 0.3443 & 0.8951 & 0.0886 & 0.0211 & 0.8897 & 0.8909 & 4.20 \\
\hline
\end{tabular}

Table A.6: Simulated water diffusion parameters for unsaturated "claystone" samples with surface water films ( $D_{e x}$ is parallel to bedding, $D_{e y}$ perpendicular to bedding).

\begin{tabular}{ccccccccc}
\hline$C V$ & $r h$ & $\theta$ & $S_{w}$ & $D_{e x} / D_{0}$ & $D_{e y} / D_{0}$ & $D_{e x} / D_{e x, s a t}$ & $D_{e y} / D_{e y, s a t}$ & $D_{e x} / D_{e y}$ \\
\hline \multirow{2}{*}{1.5} & 0.4295 & 0.1715 & 0.8813 & 0.0317 & $7.52 \mathrm{e}-03$ & 0.8024 & 0.7779 & 4.21 \\
& & & & & & & & \\
4 & 0.9190 & 0.2004 & 0.9722 & 0.0285 & $6.97 \mathrm{e}-03$ & 0.9907 & 0.9856 & 4.09 \\
& 0.8445 & 0.1815 & 0.8807 & 0.0274 & $6.67 \mathrm{e}-03$ & 0.9529 & 0.9429 & 4.11 \\
& 0.4295 & 0.1478 & 0.7173 & 0.0212 & $5.02 \mathrm{e}-03$ & 0.7380 & 0.7105 & 4.23 \\
\multirow{2}{*}{10} & 0.9190 & 0.1772 & 0.9133 & 0.0244 & $5.71 \mathrm{e}-03$ & 0.9613 & 0.9804 & 4.26 \\
& 0.8445 & 0.1541 & 0.7942 & 0.0229 & $5.38 \mathrm{e}-03$ & 0.9028 & 0.9235 & 4.25 \\
& 0.4295 & 0.1405 & 0.7239 & 0.0196 & $4.53 \mathrm{e}-03$ & 0.7717 & 0.7777 & 4.32 \\
\hline
\end{tabular}

Table A.7: Simulated anion diffusion parameters for unsaturated "claystone" samples with surface water films $\left(D_{e x}\right.$ is parallel to bedding, $D_{e y}$ perpendicular to bedding). For corresponding water contents and water saturations see Table A.6 with results for water tracers.

\begin{tabular}{|c|c|c|c|c|c|c|c|c|c|}
\hline$C V$ & $r h$ & $\theta_{a}$ & $f_{a}$ & $S_{w a}$ & $D_{e x} / D_{0}$ & $D_{e y} / D_{0}$ & $D_{e x} / D_{e x, s a t}$ & $D_{e y} / D_{e y, s a t}$ & $D_{e x} / D_{e y}$ \\
\hline 1.5 & 0.4295 & 0.0448 & 0.2613 & 0.6368 & $5.56 \mathrm{e}-03$ & $2.49 \mathrm{e}-03$ & 0.5850 & 0.6133 & 2.24 \\
\hline \multirow[t]{3}{*}{4} & 0.9190 & 0.0772 & 0.3855 & 0.9246 & $5.01 \mathrm{e}-03$ & $2.11 \mathrm{e}-03$ & 0.9849 & 0.9895 & 2.37 \\
\hline & 0.8445 & 0.0586 & 0.3228 & 0.7014 & $4.67 \mathrm{e}-03$ & $1.98 \mathrm{e}-03$ & 0.9182 & 0.9261 & 2.36 \\
\hline & 0.4295 & 0.0247 & 0.1669 & 0.2953 & $2.80 \mathrm{e}-03$ & $1.20 \mathrm{e}-03$ & 0.5499 & 0.5621 & 2.33 \\
\hline \multirow[t]{3}{*}{10} & 0.9190 & 0.0538 & 0.3039 & 0.7517 & $3.61 \mathrm{e}-03$ & $1.56 \mathrm{e}-03$ & 0.9687 & 0.9447 & 2.31 \\
\hline & 0.8445 & 0.0313 & 0.2034 & 0.4374 & $3.30 \mathrm{e}-03$ & $1.37 \mathrm{e}-03$ & 0.8855 & 0.8280 & 2.41 \\
\hline & 0.4295 & 0.0180 & 0.1279 & 0.2508 & $2.50 \mathrm{e}-03$ & $1.02 \mathrm{e}-03$ & 0.6703 & 0.6170 & 2.44 \\
\hline
\end{tabular}



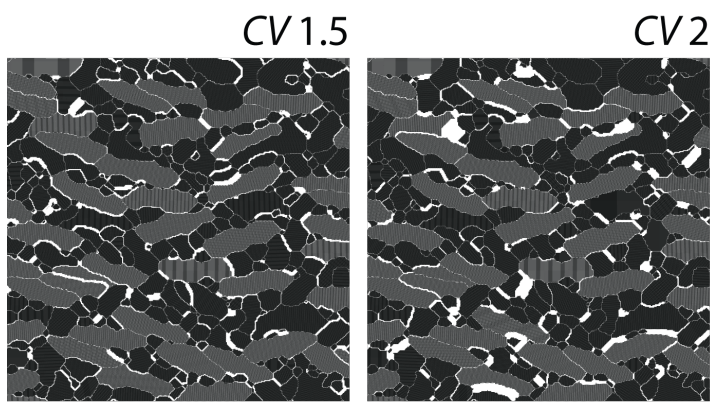

CV 2

CV 3
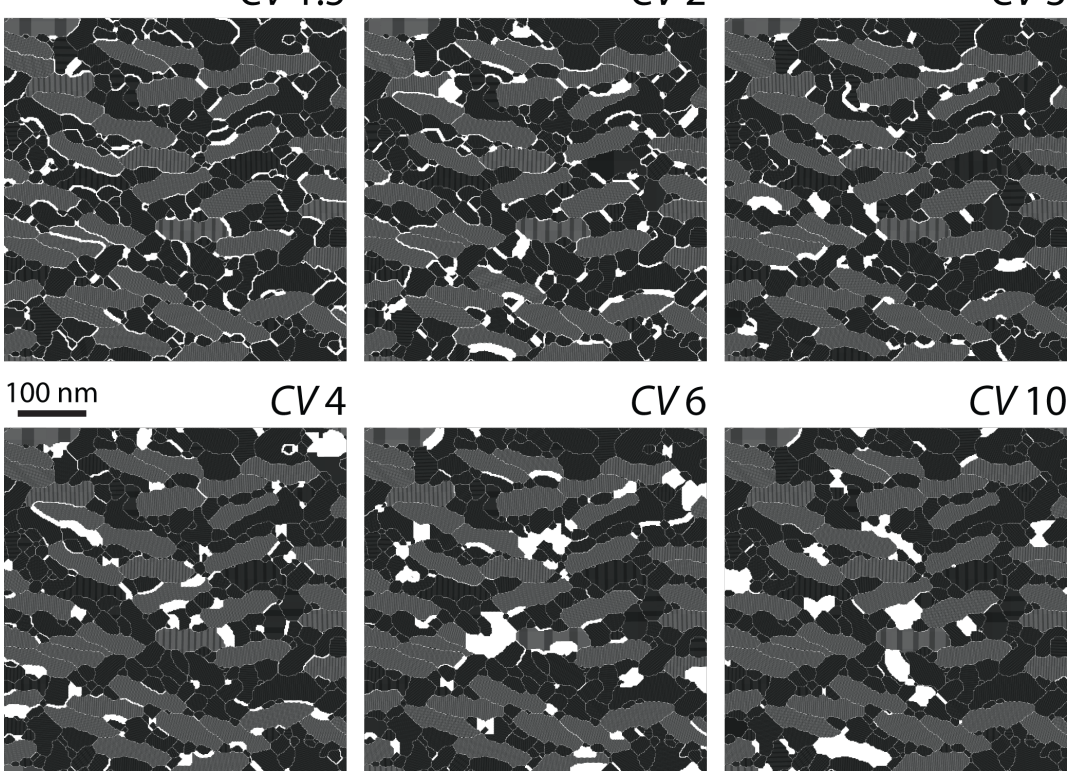

Figure 1: Upper left part (representing $6.25 \%$ of the total area) of six of the seven saturated "claystone" structure maps generated with different coefficients of variation $C V$ of the interparticle pore size distri-

bution. Particles without interlayers are black, particles with interlayers gray, and interparticle pores white. 


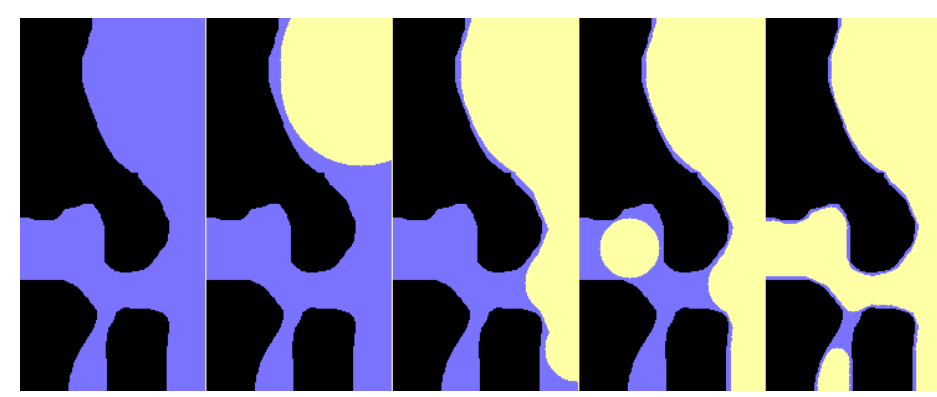

Figure 2: Illustration of drainage of a model structure map. The frames sequence from left to right corresponds to decreasing water potential. Drainage took place from all domain boundaries. The simulations included both, capillary effects (drainage of the core of pores with a decreasing radius) and surface adsorption effects (thinning of surface water films). Black: solid, blue: water, yellow: drained pore.

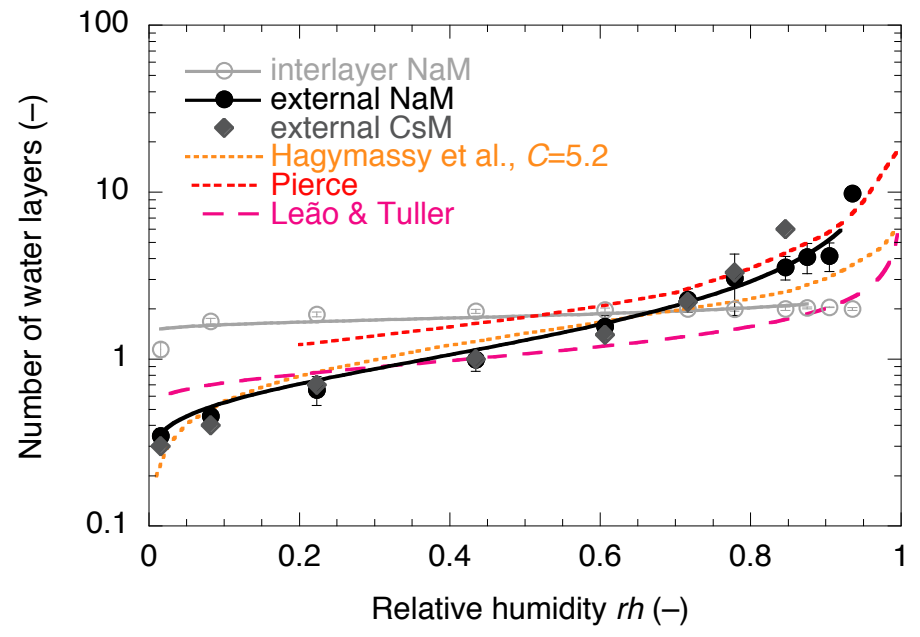

Figure 3: Calculated average number of water layers $n$ on surfaces of $\mathrm{Na}$ montmorillonite (black dots: external surface, gray circles: in interlayer) and of Cs montmorillonite (diamonds, external surface) obtained from MD simulations (Churakov 2013) as a function of the relative humidity $r h$. The black and gray lines are fitted FHH functions (see text and Table A.1), the dashed lines are some published relations (Hagymassy et al., 1969; Pierce, 1953; Leão and Tuller, 2014). 


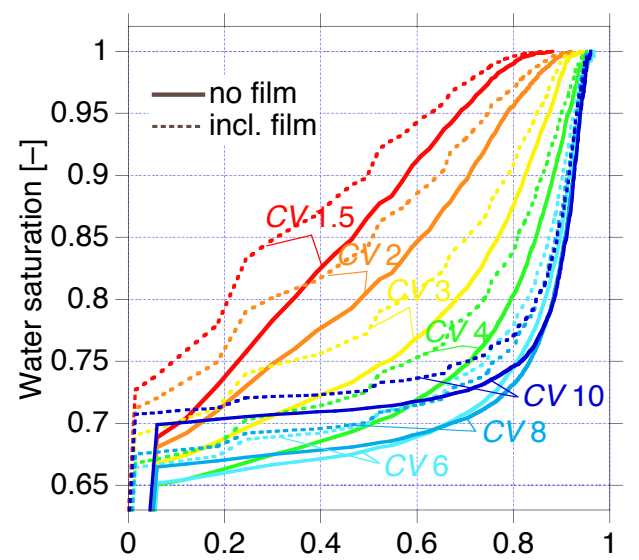

(a)

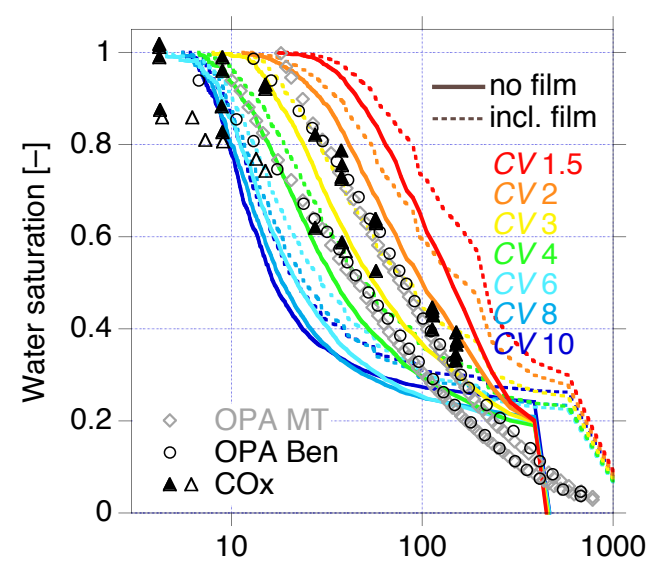

(b)

Water potential [MPa]

Figure 4: Water retention functions for the "claystone" structure maps with different $C V$ of the underlying interparticle PSD. Solid lines: capillary condensation; dashed lines: capillary condensation and adsorbed water films. (a) Water saturation vs. relative humidity. (b) Water saturation recalculated for reduced interlayer water vs. water potential, together with experimental data (drying and wetting paths) for Opalinus Clay from Mont Terri (diamonds) and Benken (circles, Gimmi, 2003), and for Callovo Oxfordian claystone (open triangles: Savoye et al., 2010; closed triangles: Wan et al., 2013).

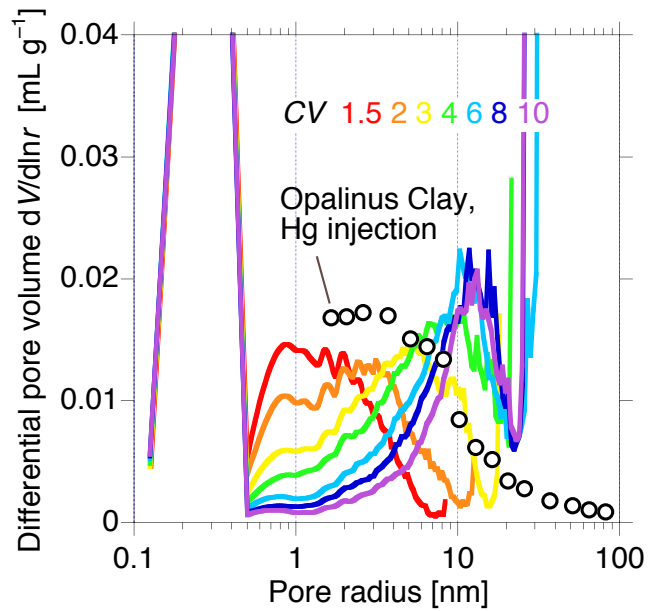

Figure 5: Pore size distributions (PSDs, smoothed) derived from the clay structure maps with different $C V \mathrm{~s}$ for the interparticle pore sizes. For comparison, the PSD of an Opalinus Clay sample derived from $\mathrm{Hg}$ injection is also shown (circles, Gimmi, 2003). 


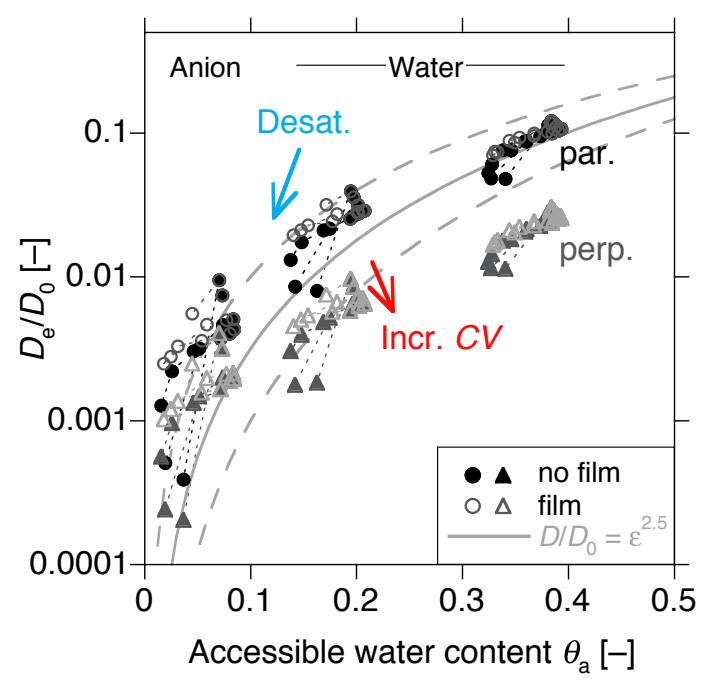

Figure 6: Overview on all simulated diffusion coefficients $D_{e} / D_{0}$ against accessible water content. $\theta_{a}<$ 0.1 : anion in "claystone"; $0.1<\theta_{a}<0.22$ : water tracer in "claystone", $0.3<\theta_{a}<0.4$ : water tracer in "smectite". Values parallel (circles) and perpendicular to bedding (triangles), ignoring (closed symbols) or including surface water films (open symbols). The blue arrow and the thin dashed lines exemplify desaturation effects for each structure and tracer combination (see also Figure 7). The red arrow indicates the effect of increasing $C V$ of the structure maps (all shown with identical symbols). The gray lines represent Archie curves with exponents of 2.5 (solid), 2, and 3 (dashed, upper and lower curve). 


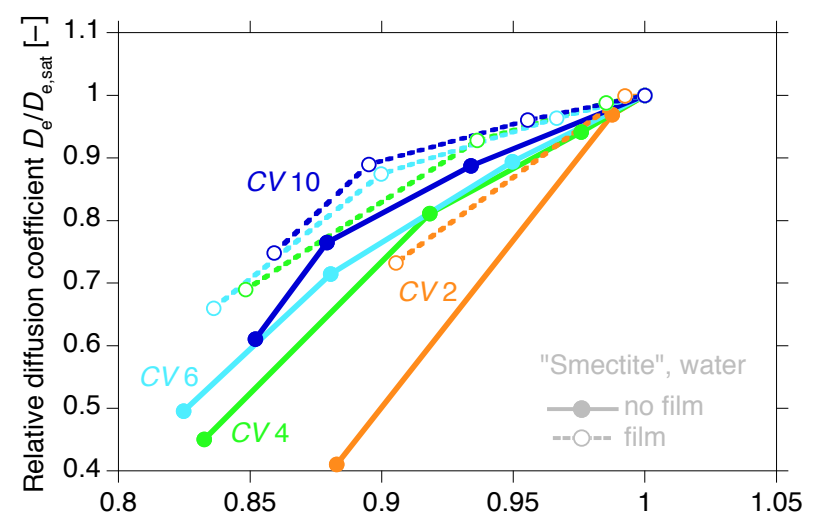

(a)

Water saturation $[-]$

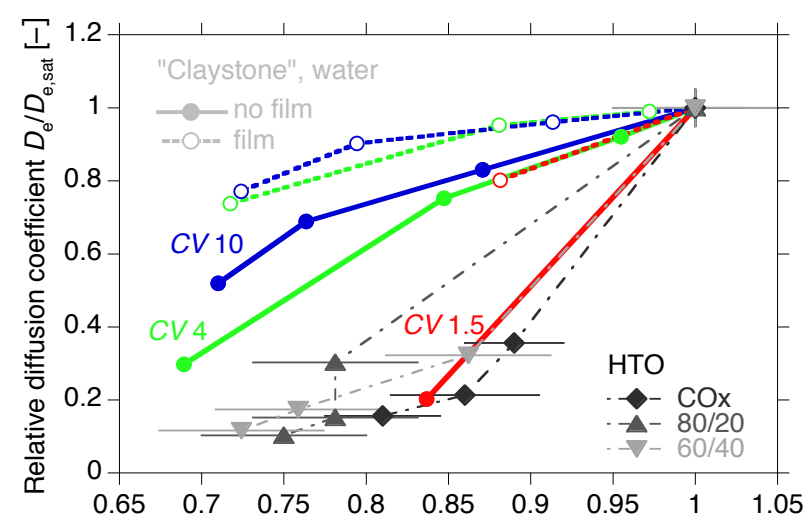

(b)

Water saturation $[-]$

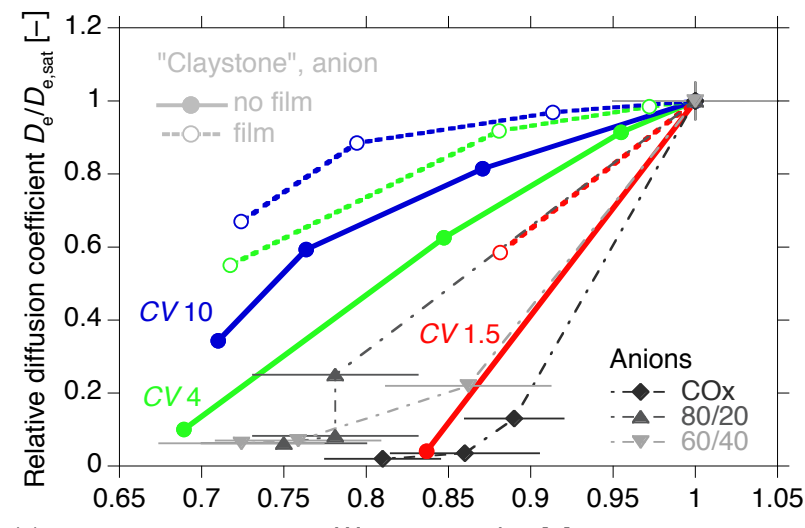

(c)

Water saturation $[-]$

Figure 7: Simulated diffusion coefficients $D_{e} / D_{e, s a t}$ (parallel to bedding) for clay structure maps with various $C V$ as a function of water saturation. (a) Water in "smectite" structures; (b) water in "claystone" structures (smectite and non-smectite particles); (c) anion in "claystone" structures. Solid lines: only capillary condensation; dashed lines: capillary condensation and surface films. Symbols with dashdotted lines: experimental data of Savoye et al. $(2010,2014)$ for Callovo Oxfordian claystone (COx) and illite/sand mixtures (80/20 and 60/40). 


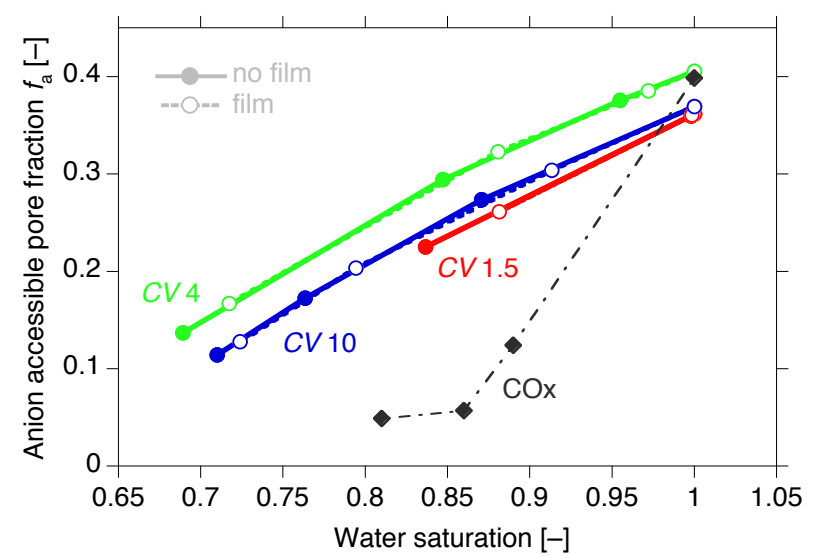

Figure 8: Dependence of the simulated anion accessible pore fraction $f_{a}=\theta_{a} / \theta$ on the water saturation for structure maps with different $C V$ considering only capillary condensation (solid lines) or additionally also surface water films (dashed lines). Symbols with dash-dotted lines: experimental data of Savoye et al. (2010) for Callovo Oxfordian claystone.
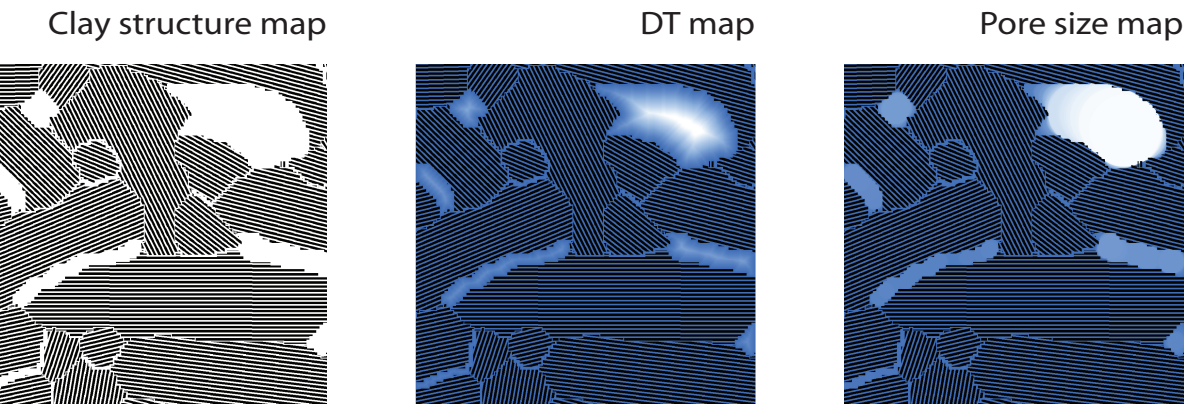

Figure A.1: Illustration of the main steps of the pore size distribution analysis. Left: A small domain of a generated clay structure map. Middle: Corresponding distance transform (DT) map. Right: Derived pore size (PS) map. The different values of the DT and the PS map are colour coded. 
No surface films

rh 0.84

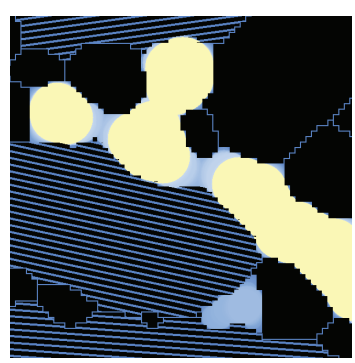

With surface films

rh 0.84

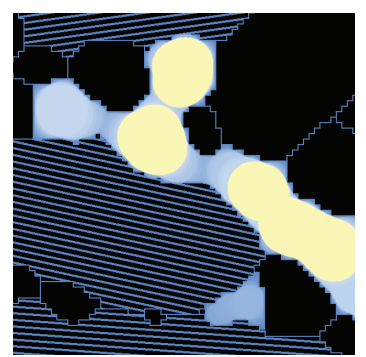

Difference

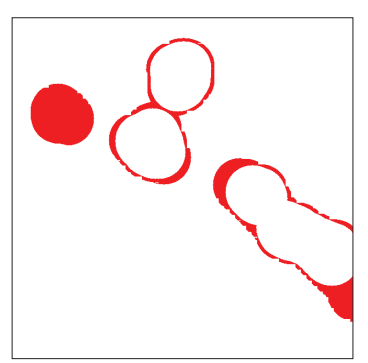

Figure A.2: Details of differences in water retention at a relative humidity $r h$ of 0.84 in a small part of a clay structure map. Air-filled pores (yellow) and water-filled pores (different shades of blue, with lighter values for larger equivalent pore sizes) in clay without (left) and with (middle) surface water films, as well as difference in water content at this $r h$ when considering films (right). 


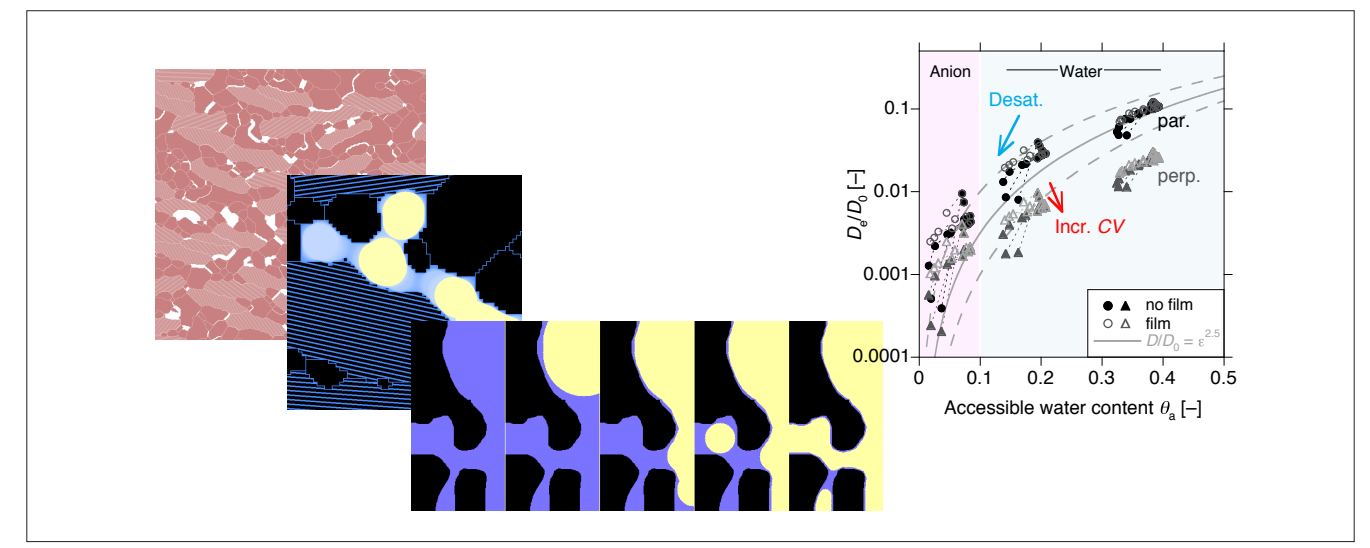

Graphical Abstract 